\title{
A sustainable development pathway for climate action within the UN 2030 Agenda
}

\author{
Bjoern Soergel ${ }^{1 凶}$, Elmar Kriegler ${ }^{1,2}$, Isabelle Weindl ${ }^{1}{ }^{1}$, Sebastian Rauner ${ }^{1}{ }^{1}$, Alois Dirnaichner', \\ Constantin Ruhe $\mathbb{1}^{3,4}$, Matthias Hofmann ${ }^{1}$ 1, Nico Bauer ${ }^{1}$ 1, Christoph Bertram $(\mathbb{1}$ ', \\ Benjamin Leon Bodirsky ${ }^{(1)}$, Marian Leimbach ${ }^{(1)}$, Julia Leininger ${ }^{4}{ }^{4}$, Antoine Levesque $\mathbb{D}^{1}$, \\ Gunnar Luderer ${ }^{1}$ 1,5, Michaja Pehl(1), Christopher Wingens ${ }^{4}$ 4, Lavinia Baumstark ${ }^{1}$ ', Felicitas Beier', \\ Jan Philipp Dietrich ${ }^{1}$, , Florian Humpenöder ${ }^{1}$ ', Patrick von Jeetze ${ }^{\circledR 1}$, David Klein', Johannes Koch $\mathbb{1}^{1}$, \\ Robert Pietzcker ${ }^{1}{ }^{1}$, Jessica Strefler ${ }^{1}{ }^{1}$, Hermann Lotze-Campen ${ }^{10}{ }^{1,6}$ and Alexander Popp ${ }^{1}$
}

\begin{abstract}
Ambitious climate policies, as well as economic development, education, technological progress and less resource-intensive lifestyles, are crucial elements for progress towards the UN Sustainable Development Goals (SDGs). However, using an integrated modelling framework covering 56 indicators or proxies across all 17 SDGs, we show that they are insufficient to reach the targets. An additional sustainable development package, including international climate finance, progressive redistribution of carbon pricing revenues, sufficient and healthy nutrition and improved access to modern energy, enables a more comprehensive sustainable development pathway. We quantify climate and SDG outcomes, showing that these interventions substantially boost progress towards many aspects of the UN Agenda 2030 and simultaneously facilitate reaching ambitious climate targets. Nonetheless, several important gaps remain; for example, with respect to the eradication of extreme poverty (180 million people remaining in 2030). These gaps can be closed by 2050 for many SDGs while also respecting the $1.5^{\circ} \mathrm{C}$ target and several other planetary boundaries.
\end{abstract}

A transformation towards sustainability requires tackling multiple crises simultaneously. By adopting an ambitious agenda for fostering human well-being within planetary boundaries-the Paris Agreement and the sustainable development goals (SDGs) - world leaders acknowledged this urgent need in 2015. However, 5 years into both of these agreements, reviewing the progress towards their targets is sobering ${ }^{1,2}$. Given the narrow 2030 time horizon of the SDGs and the risk of losing achievability of the Paris climate targets ${ }^{3}$, it is important to assess how synergies between climate action and other SDGs can be fully exploited through rapid and coordinated action, and which interventions are required to do $\mathrm{so}^{4,5}$.

Modelling pathways towards a sustainable future requires quantitative coverage of the SDG space, including the interconnections between $\mathrm{SDGs}^{6-13}$. For example, ambitious climate action has cobenefits and trade-offs for other objectives ${ }^{14-19}$. While trade-offs affect land use, biodiversity ${ }^{20}$, food prices $^{21,22}$ and energy access ${ }^{23,24}$, these can be softened by more integrated policy-making ${ }^{25-27}$. While a few existing studies quantify multiple sustainability indicators ${ }^{18,26,28,29}$ or include additional sustainability measures ${ }^{26,28,30}$, overall existing scenarios cover only a small part of the SDG space and do not meet many of the targets ${ }^{31,32}$.

Here, we structure integrated strategies towards sustainable development along six interventions A-F (Extended Data Fig. 1) and study their interaction within a scenario framework. Interventions A (development) and B (resource efficiency and lifestyle change) align with the sustainability scenario (SSP1) from the shared socioeconomic pathways ${ }^{33}$. Intervention $\mathrm{C}$ introduces ambitious climate change mitigation, for which previous modelling studies $^{30,34,35}$ have already highlighted the synergies of interventions A and B. Our study identifies an additional set of synergistic interventions to boost progress towards many aspects of the Agenda 2030: a 'climate and development' scheme connects international climate finance (intervention E) with national poverty alleviation programmes financed from carbon pricing revenues (F). We further include a deepened shift in consumption patterns combined with energy- and land-system sustainability policies (together intervention $\mathrm{D}$ ). The shift includes a comprehensive transition towards sufficient, healthy and sustainable nutrition ${ }^{36}$, enhanced access to modern energy in developing regions and a more ambitious lifestyle shift in industrialized economies.

We quantify the role of this sustainable development package, in concert with interventions $\mathrm{A}-\mathrm{C}$, in a sustainable development pathway (SDP) scenario. Our analysis integrates the coupled energy-economy-land-climate modelling framework REMINDMAgPIE $^{37}$ with several additional models (Extended Data Fig. 2). We cover 56 SDG indicators or proxies from all 17 SDGs, which are selected from a condensed SDG target space $8,31,32$ and/or through a mapping to the official SDG targets and indicators. This comprehensive (albeit still incomplete) set comprises indicators relating to (1) scenario assumptions, (2) endogenous outcomes from the main REMIND-MAgPIE framework or (3) results from downstream models. We include the effects of rising $\mathrm{CO}_{2}$ concentrations on the oceans and projections for the development of political institutions

'Potsdam Institute for Climate Impact Research (PIK), Member of the Leibniz Association, Potsdam, Germany. ${ }^{2}$ Universität Potsdam, Potsdam, Germany. ${ }^{3}$ Goethe-Universität, Frankfurt am Main, Germany. ${ }^{4}$ German Development Institute-Deutsches Institut für Entwicklungspolitik (DIE), Bonn, Germany. ${ }^{5}$ Global Energy Systems Analysis, Technische Universität Berlin, Berlin, Germany. ${ }^{6}$ Humboldt-Universität zu Berlin, Berlin, Germany.

凶e-mail: soergel@pik-potsdam.de 
and peace (the absence of violent conflict), as in particular the last two are key for an effective and inclusive implementation of the Agenda 2030.

The SDP scenario developed in this study outlines an ambitious pathway for substantial progress towards many aspects of the Agenda 2030. At the same time, it highlights which SDGs are challenging to achieve by 2030 and even by 2050 , and thus sheds light on bottlenecks and trade-offs between different targets.

\section{Results}

We contrast our SDP scenario with a number of other SSP scenarios with different climate policy ambition levels to highlight the effects of the different interventions on SDG outcomes (Extended Data Fig. 1). These scenarios include a continuation of historical trends with further incremental climate policies according to the nationally determined contributions (SSP2-NDC), and a push towards more rapid development and less resource-intensive lifestyles (interventions A and B, SSP1-NDC). Adding ambitious climate policies compatible with the $1.5^{\circ} \mathrm{C}$ target $(\mathrm{C})$ yields the SSP1-1.5C scenario that resembles existing sustainability-focused mitigation pathways ${ }^{3}$. Our SDP-1.5C scenario additionally includes a package of sustainable development interventions (D-F).

Importantly, we represent some interventions through explicit policy measures (for example, carbon pricing in intervention $\mathrm{C}$ and redistributive measures in $\mathrm{E}$ and $\mathrm{F}$ ). For other interventions, we capture their outcome through a scenario assumption without explicitly resolving the underlying policy measures or societal trends (for example, healthier diets and improved energy access in intervention $\mathrm{D}$ and better education in $\mathrm{A})$. Some interventions also reflect societal trends that go hand-in-hand with associated policy measures. An overview of the interventions and their representation in our modelling framework is given in Supplementary Tables 2 and 3.

For discussion of SDG indicator outcomes we group them into the five major clusters ${ }^{32}$ : planetary integrity; provision of material needs; people; prosperity; and political institutions, peace, partnership. As a high-level summary of our results, we show a selection of global SDG indicators in Fig. 1. Subsequently we discuss the effects of the different interventions and the remaining SDG achievement gap both at the global and regional level. Our main discussion largely focuses on one headline indicator for most SDGs. More detailed results and a discussion of the full indicator set for all SDG clusters are available in the extensive Supplementary Information. We provide a list of our indicators, their relation to the official SDG targets and a categorization into scenario assumptions, endogenous model results and further postprocessing in Supplementary Table 1.

Planetary integrity (SDGs 13, 14 and 15). Averting dangerous climate change and preserving the integrity of the biosphere ${ }^{38}$ provide the essential foundation for long-term human well-being on planet Earth. As high-level proxies for planetary integrity, we consider annual GHG emissions, global mean temperature (GMT) increase, the aragonite saturation state (ocean acidification), the biodiversity intactness index (BII) and the industrial and intentional biological fixation of nitrogen in agriculture (Fig. 1).

In our SDP scenario, global GHG emissions are reduced rapidly, dropping to $33 \mathrm{GtCO}_{2} \mathrm{e} \mathrm{yr}^{-1}$ in 2030 and to $10 \mathrm{GtCO}_{2} \mathrm{e} \mathrm{yr}^{-1}$ in 2050. Notably, a rapid reduction of agricultural $\mathrm{CH}_{4}$ and $\mathrm{N}_{2} \mathrm{O}$ emissions beyond what has been reported for $1.5^{\circ} \mathrm{C}$ pathways in the literature ${ }^{3}$ allows meeting the $1.5^{\circ} \mathrm{C}$ target with a $100 \mathrm{Gt}$ higher $\mathrm{CO}_{2}$ budget ${ }^{39}$, facilitating the transition in energy and transport and reducing the need for $\mathrm{CO}_{2}$ removal technologies considerably ('Climate policy' in Methods and Supplementary Fig. 1). The median warming in our SDP scenario barely overshoots the $1.5^{\circ} \mathrm{C}$ target and returns to $\sim 1.3^{\circ} \mathrm{C}$ warming by the end of the century. Furthermore, ocean acidification is halted at aragonite saturation levels preventing adverse conditions for the dominant marine calcifying organisms ${ }^{40}$.
While in both ambitious mitigation scenarios primary forest is fully conserved and loss of terrestrial biodiversity is halted, only the SDP scenario achieves modest improvements in biodiversity by mid-century $(\mathrm{BII}=0.8$ in 2050). It also breaks the ever-increasing trend in the human impact on the nitrogen cycle, reducing human-induced nitrogen fixation to around $120 \mathrm{MtNyr}^{-1}$ in 2050, which is, however, still around one-third above the suggested planetary boundary ${ }^{36}$.

Provision of material needs and sustainable resource management (SDGs 2, 6, 7 and 12). This second cluster encompasses the universal provision of basic material needs, while simultaneously managing natural resources in a sustainable way. Above all, this means a world without hunger and with universal access to clean water and modern energy.

Our SDP scenario assumes an achievement of zero hunger by 2050 and a reduction of malnourishment by nearly half by 2030 , taking into account the required higher food demand. We further assume that diets gradually shift towards healthy and sustainable patterns with less animal protein as recommended by the EATLancet Commission ${ }^{36}$ and that the trend of increasing food waste can be reversed. As a consequence, we find no major trade-off between sufficient nourishment for the global population and the environmental indicators associated with food production ${ }^{41,42}$. For example, agricultural water use can be reduced by more than a quarter by 2050 . This brings agriculture, which accounts for the lion's share of human water use today, in line with planetary boundaries ${ }^{38}$. The reduced pressure on land also eliminates food price increases seen in the SSP1-1.5C scenario (compare against Fig. 2), underpinning the faster decrease of malnourishment in the SDP scenario.

We consider per-capita (cap) useful energy (UE) consumption for buildings and mobility as a proxy for access to modern energy services in developing regions, as it directly captures the energy available for the service after accounting for conversion efficiencies. For our SDP scenario we project an increase to $6.4 \mathrm{GJ} \mathrm{cap}^{-1} \mathrm{yr}^{-1}$ in 2030 and to $15 \mathrm{GJ} \mathrm{cap}^{-1} \mathrm{yr}^{-1}$ in 2050, around $75 \%$ (2030) and $320 \%$ (2050) above the current (2015) value and largely sufficient to meet energy requirements for decent living standards ${ }^{43}$. Over the same time horizon, the average value in Organisation for Economic Co-operation and Development (OECD) regions decreases by $>20 \%$ to $36 \mathrm{GJ} \mathrm{cap}^{-1} \mathrm{yr}^{-1}$, reflecting a transition away from energy-intensive lifestyles (Supplementary Figs. 6 and 21 provide final energy values and a breakdown into demand sectors and regions).

People (SDGs 1, 3, 4 and 5). Eradicating extreme poverty, providing for people's health and ensuring access to education and gender equality represent the human development core of the Agenda 2030. We project that the prevalence of extreme poverty will be reduced to around 180 million people (poverty rate $2.3 \%$ ) in our SDP scenario by 2030 , a substantial reduction compared to the around 750 million people (10\%) in 2015. However, it is not sufficient to fully reach the target of zero poverty, which is achieved only by 2050 .

The transition away from fossil fuels substantially reduces the detrimental effects of outdoor air pollution on public health. We find that the SDP scenario leads to 5 million fewer disability adjusted life years lost annually in 2030 compared to current (2015) levels and around 25 million fewer in 2050. This is similar to the SSP1$1.5 \mathrm{C}$ scenario, despite the slightly higher $\mathrm{CO}_{2}$ budget and the larger energy demands in developing regions in the SDP. Nonetheless, health and mortality impacts from air pollution remain well above the target levels estimated from WHO guidelines (Supplementary Fig. 9 and SDG 11, as described below).

On the basis of the SSP1 education data, which we also assume in the SDP scenario, the share of the adult population without school education decreases continuously. However, due to the older cohorts with worse education histories, the decrease is insufficient to meet 


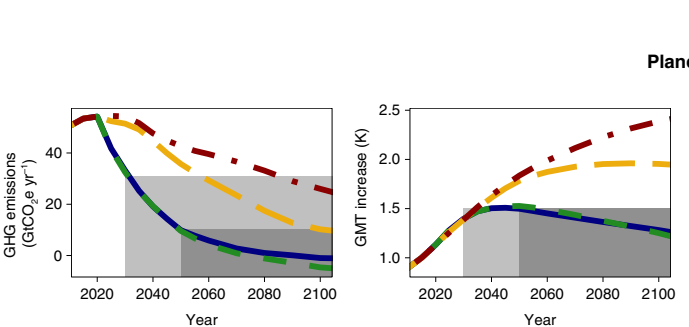
Planetary integrity
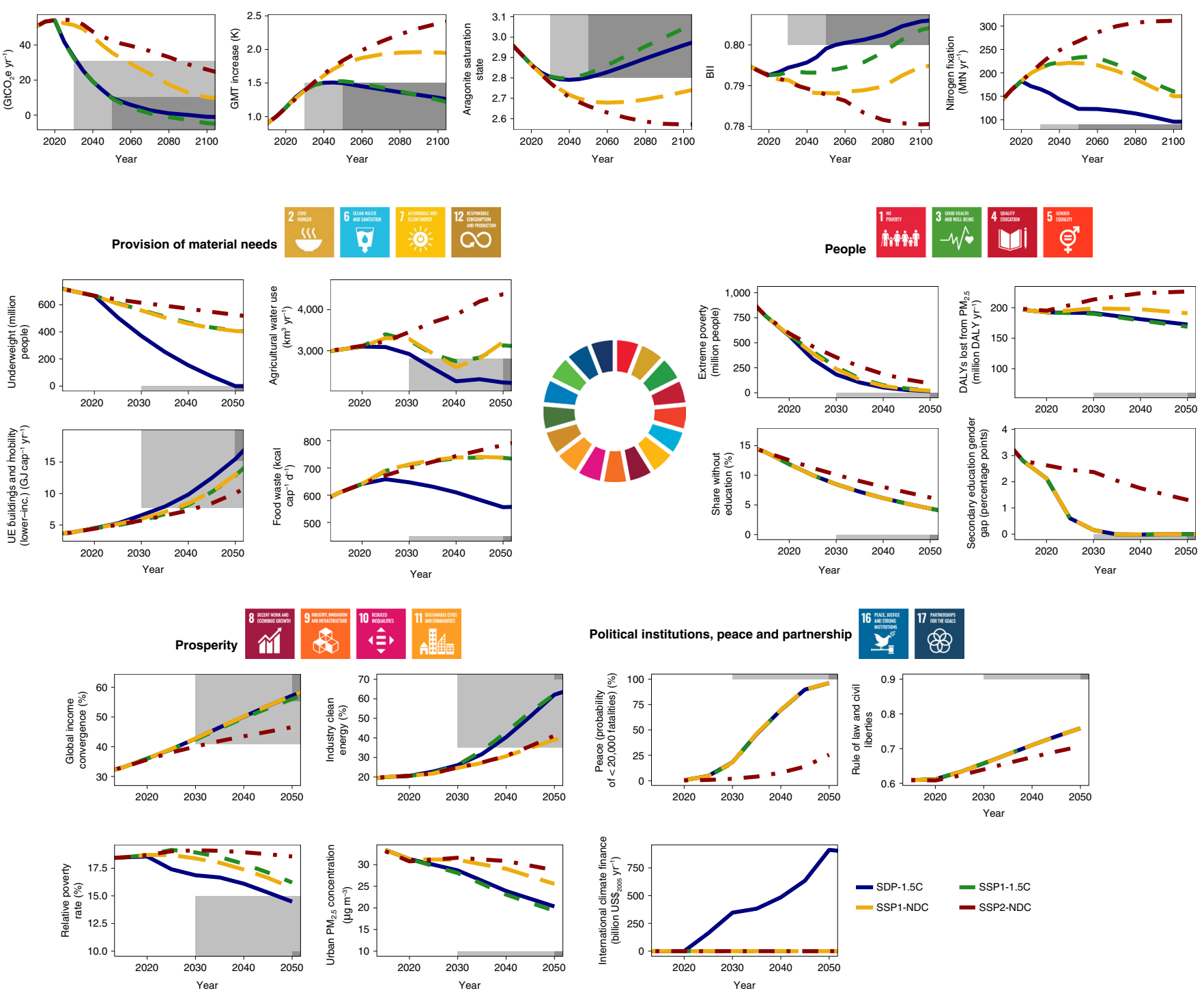

Fig. 1 | Overview of headline SDG indicator values grouped into five clusters. We compare our sustainable development pathway scenario (SDP-1.5C) to a number of other scenarios (main text). Grey shaded areas illustrate the target values (light shading for 2030 and dark shading for 2050), where available. All indicators are global sums or (population-weighted) averages, with the exception of useful energy (UE) per capita where we show an average of lower-income regions (REMIND-MAgPIE regions, Sub-Saharan Africa, India, East Asian countries except for China and Japan). 'Global income convergence' is the ratio of global GDP per capita to the OECD GDP per capita. For the 'planetary integrity' cluster we show results until 2100; otherwise, we restrict them to the time horizon until 2050. DALYs, disability adjusted life years; $\mathrm{PM}_{2.5}$, fine particulate matter (diameter $<2.5 \mu \mathrm{m}$ ); cap, capita; BII, biodiversity intactness index.

the aspirational target of zero by 2030 or even by 2050 . Considering only the school-leaving cohorts, the improvements are substantially more pronounced (Supplementary Fig. 10). For the last group, also the gender education gap (the difference between genders in lower secondary education completion shares) nearly closes by 2030 .

Prosperity (SDGs 8, 9, 10 and 11). The aspiration underlying the SDGs is to provide both prosperous and sustainable living conditions for all global citizens. We quantify this using metrics of between- and within-country inequality, together with indicators for industry sustainability and living conditions in cities.

Our SDP scenario assumes a convergence of income levels between countries: the ratio of global average gross domestic product (GDP) per capita to the OECD value increases from 33\% in 2015 to $43 \%$ in 2030 and to $57 \%$ in 2050 (in purchasing power parity, PPP). However, despite rapid income growth in developing regions, regional disparities remain, with Sub-Saharan Africa reaching only $10 \%(21 \%)$ of the OECD GDP per capita in 2030 (2050). Inequality within countries is reduced steadily, with the fraction of the population in relative poverty (below $50 \%$ of the national median income) decreasing from a global average of $18.5 \%$ in 2015 to $16.9 \%$ in 2030 and $14.5 \%$ in 2050 .

The transition to cleaner production methods in industry starts off at modest pace due to the inertia of existing capital stocks, with the share of clean energy (electricity and hydrogen) in global industrial energy increasing only modestly to $26 \%$ in 2030 . The transition subsequently accelerates, driven by cheaper renewable electricity, using the full potential of demand-side electrification ${ }^{44}$ and reaching 

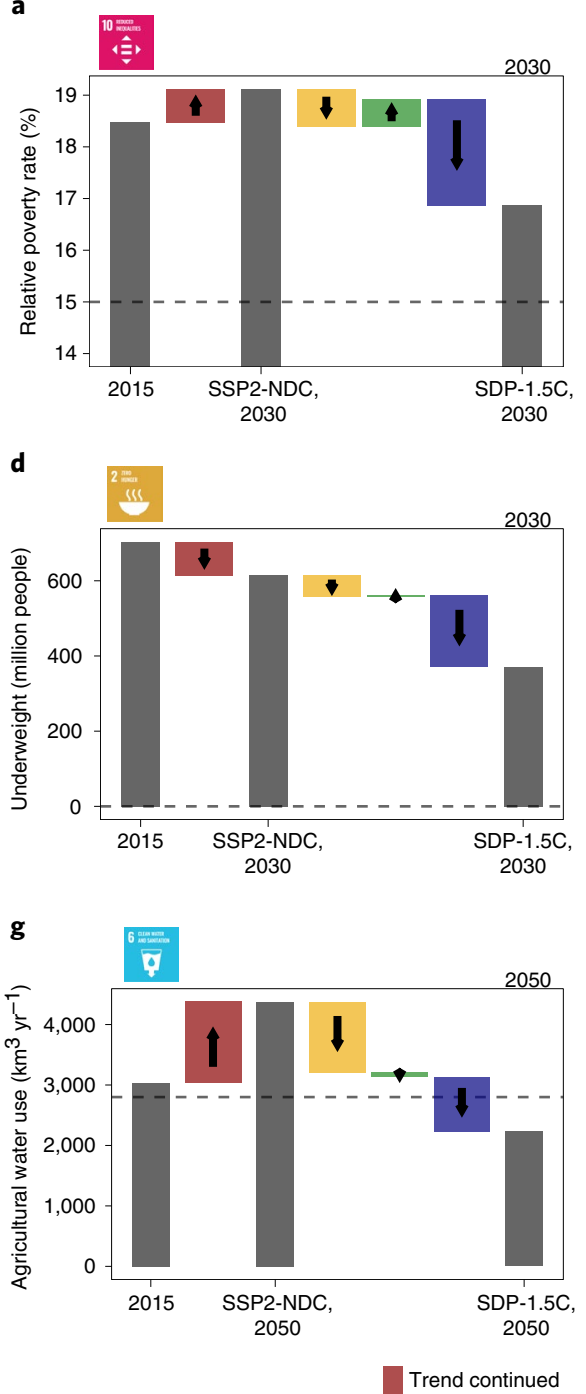

b

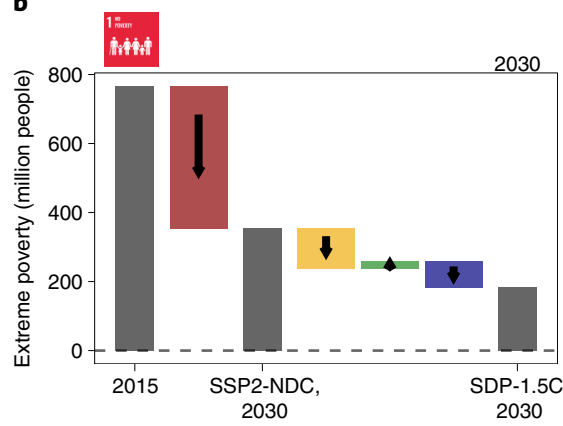

e

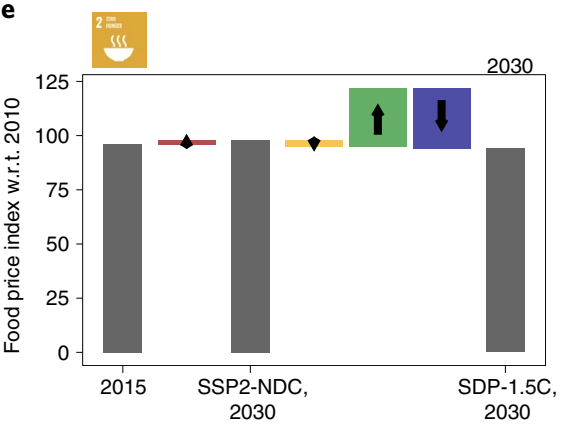

h

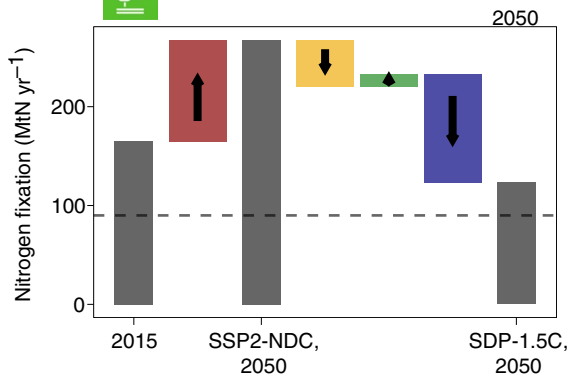

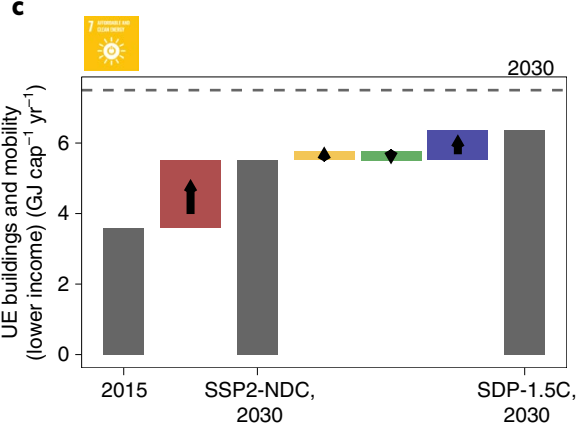

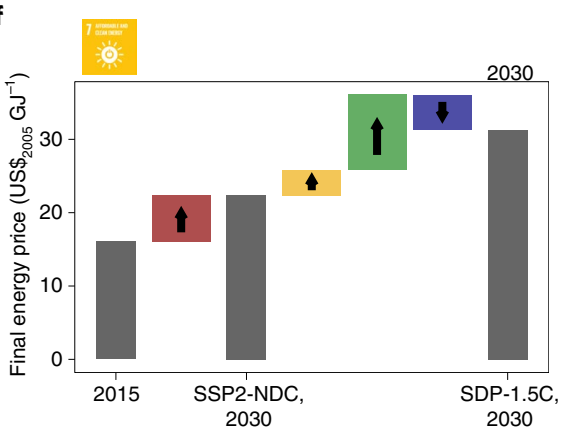

i

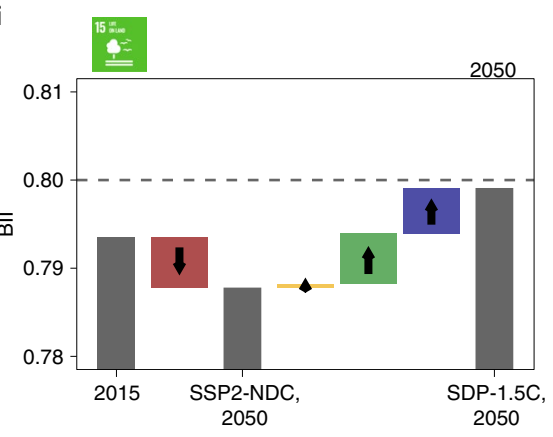

SD interventions (D,E,F)

Fig. 2 | Decomposition of SDG outcomes, highlighting the effects of the different interventions. $\mathbf{a}$, Relative poverty rate. $\mathbf{b}$, Extreme poverty. $\mathbf{c}$, UE buildings and mobility (lower-income). d, Underweight. e, Food price index. f, Final energy price. $\mathbf{g}$, Agricultural water use. h, Nitrogen fixation. i, Bll. The first step in dark red denotes the trend from 2015 to 2030 (or 2050) assuming no major break with recent historical trends and the implementation of current NDCs (SSP2-NDC). The second step illustrates the shift to a pathway with more rapid development, higher resource efficiency and more environmentally conscious lifestyles (SSP1-NDC, yellow), while the third step shows the addition of an ambitious, Paris-compliant climate policy (SSP1-1.5C, green). The final step, representing the major innovation of this paper, illustrates the added value of additional sustainable development interventions in the domains of inequality and poverty, nutrition and energy access, as well as additional energy and land-use policies (SDP-1.5C, blue). The first two rows of indicators show SDG-related outcomes in 2030; the final row relates to planetary boundaries in 2050. Target values for 2030 (2050) are indicated by the dashed lines.

a clean energy share of $62 \%$ by 2050 . The transition away from fossil fuels reduces urban air pollution substantially, with the globally averaged concentration of particles with diameter $<2.5 \mu \mathrm{m}\left(\mathrm{PM}_{2.5}\right)$ in cities being reduced by around $40 \%$ by 2050 . However, increased energy demands in developing regions partially offset air pollution benefits from decarbonizing the energy supply.

Political institutions, peace and partnership (SDGs 16 and 17). Governing the ambitious transformation to sustainability requires peace, strong national and global institutions and extensive global cooperation $^{45-47}$. SDG 16 and 17 are therefore targets but also preconditions for sustainable development ${ }^{27}$. The optimistic socioeconomic scenario assumptions for the SSP1 and SDP scenarios therefore imply strong institutions and peace (intervention A; Extended Data Fig. 1). To capture these two factors quantitatively, we model for each country the quality of rule of law and individual liberties ${ }^{48}$ and the number of armed conflict fatalities ${ }^{49,50}$. The SDP and the SSP1 scenarios describe overall converging institutional quality but nevertheless substantial regional differences remain. The global population-weighted average of the institutional quality indicator (range 0-1) improves moderately from 0.61 in 2015 to 0.76 in 2050 but falls short of the target value of 0.9 (ref. ${ }^{32}$ ). All scenarios project further declining numbers of armed conflict fatalities (following a recent maximum of $>140,000$ fatalities in 2014); however, initially only at a slow pace. By 2050, only the SDP and SSP1 scenarios project a substantial probability of reducing armed fatalities to $<20,000$ fatalities (the recent minimum in 2005). However, these projections are associated with considerable uncertainty, since our models include only those structural covariates of institutional quality and peace for which long-term scenario projections currently exist.

Mitigating climate change requires global cooperation and effort sharing; thus, our SDP scenario assumes that international climate 


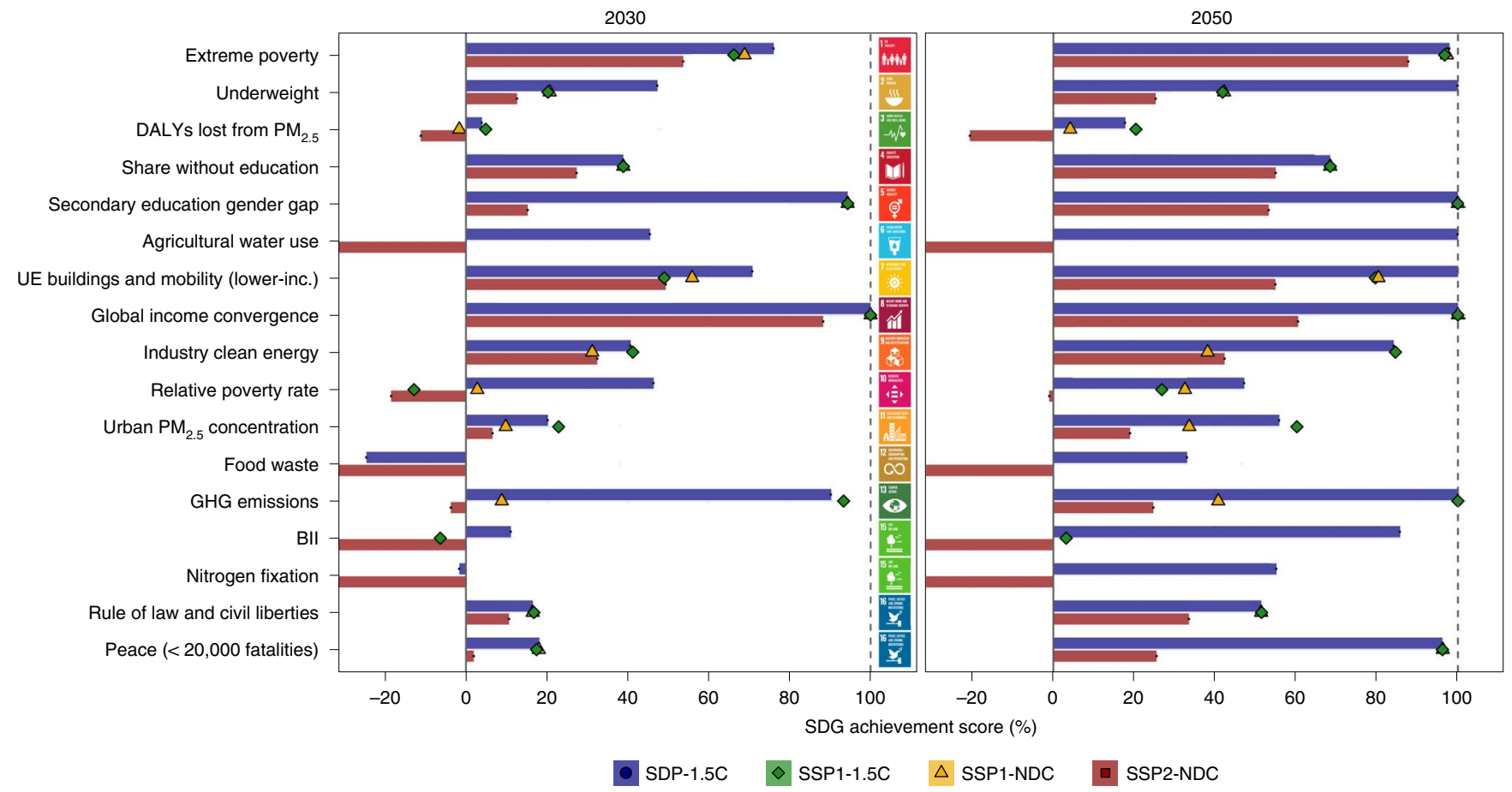

Fig. 3 | Global SDG achievement and gap analysis for selected indicators. A value of zero represents the value of the indicator in 2015 , whereas $100 \%$ indicates that the target is fully met or even exceeded. SSP2-NDC and SDP-1.5C scenarios are shown as bars, the 'intermediate' scenarios SSP1-NDC and SSP1-1.5C using symbols. The left side shows results for 2030, whereas the right is for 2050. An overview of the targets used is given in Supplementary Table 1. In some cases, 2050 targets are more ambitious than 2030 targets. Negative values represent a worsening of the situation. We have cut the scale at $-30 \%$ but note that the indicators 'agricultural water use', 'food waste', 'BII' and 'nitrogen fixation' deteriorate far beyond this value in the SSP2-NDC scenario (absolute values compared to the targets are shown in Fig. 1). With the exception of 'useful energy buildings and mobility', which shows the average value of lower-income regions, all indicators are global sums or averages. Aragonite saturation (SDG 14) was excluded, as current values are so close to the target value that the gap indicator is not meaningful.

finance is scaled up rapidly and goes beyond the US $\$ 100$ billion $\mathrm{yr}^{-1}$ target for 2020. We use a stylized 'climate and development' package that operationalizes the 'partnership for the goals' (SDG 17) and leads to international transfers of around US\$350 billion $\mathrm{yr}^{-1}$ in 2030 , increasing to US $\$ 10$ billion $\mathrm{yr}^{-1}$ by 2050 (note that we use US $\$_{2005}$ unless otherwise noted). These funds are used to finance poverty alleviation policies (section titled 'Burden sharing and climate \& development finance' in Methods).

Effects of different interventions, synergies and trade-offs. We decompose the changes in SDG indicator values into a continuation of current trends and the effects of the different interventions (Fig. 2), classifying indicators according to (1) positive or negative current trends and (2) synergies or trade-offs with climate policies. More rapid development and resource efficiency (interventions $A$ and B) improve nearly all indicators but in many cases a large gap to the target values remains, particularly for indicators with a combination of negative current trends and trade-offs with climate policy.

The clean energy share in industry and the air pollution concentration in cities show positive trends and synergies with climate policies (not shown in Fig. 2). Most developmental indicators (for example, extreme poverty and energy access) also have positive trends but show trade-offs with climate policies, largely driven by higher energy and food prices (Fig. 2a-f). By contrast, most environmental indicators display worsening trends (Fig. $2 g-i$ ). While biodiversity and ocean acidification improve with mitigation policies, agricultural water use is largely unaffected and nitrogen fixation shows a modest trade-off. The direction and magnitude of climate policy side-effects does not change substantially when reversing the order of the decomposition (Supplementary Information section 3 and Supplementary Fig. 18).

Our additional sustainable development interventions (D-F) particularly improve the indicators for inequality, energy access and food security and compensate (reduce) the rise of food (energy) prices (Fig. 2a-f). A decomposition into the individual interventions highlights the synergy between international transfers (E) and national redistribution $(\mathrm{F})$ for reducing extreme poverty (Extended Data Fig. $3 \mathrm{~b}$ and Supplementary Information section 3). Further splitting intervention $\mathrm{D}$ into food- and energy-related parts reveals that the shift to a healthy and sustainable diet ( $\mathrm{D}$, food) limits energy price increases by increasing the $1.5^{\circ} \mathrm{C}$-compatible $\mathrm{CO}_{2}$ budget (Extended Data Fig. 3f); however, at the expense of a marginally worse ocean acidification and environmental footprint of energy supply.

We furthermore find pronounced cobenefits for environmental pressures in the land-use system, reducing agricultural water use and human-induced nitrogen fixation and reverting the trends of biodiversity loss (Fig. 2g-i).

Global SDG achievement and gaps. There is considerable progress in closing the gap between current (2015) indicator values and their targets in our SDP scenario, especially compared to the SSP2-NDC reference scenario (Fig. 3). While the improvements are insufficient to achieve most of the targets for our headline indicators by 2030, there is substantial further progress until 2050, such that many targets are (nearly) met by then. For example, extreme poverty is reduced to nearly zero and underweight is eradicated (the latter by assumption), while at the same time the planetary boundaries on GHG emissions, water use and biodiversity intactness are largely respected. 
a

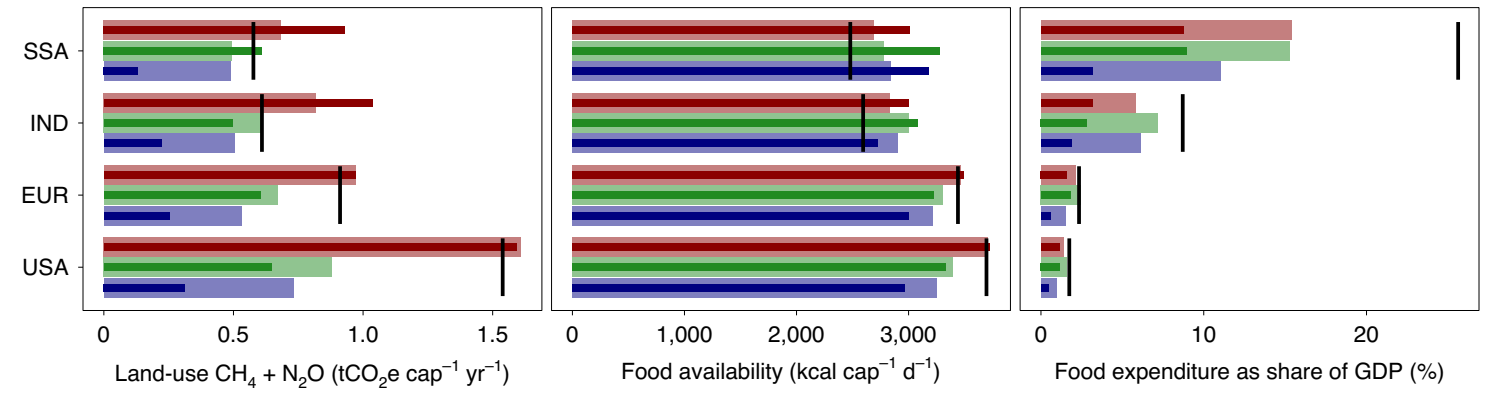

b
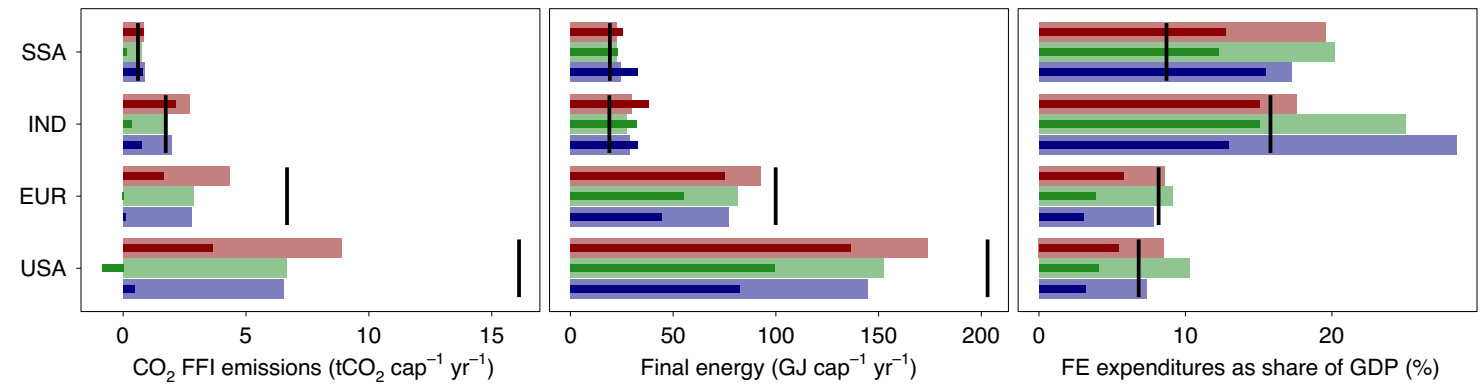

c
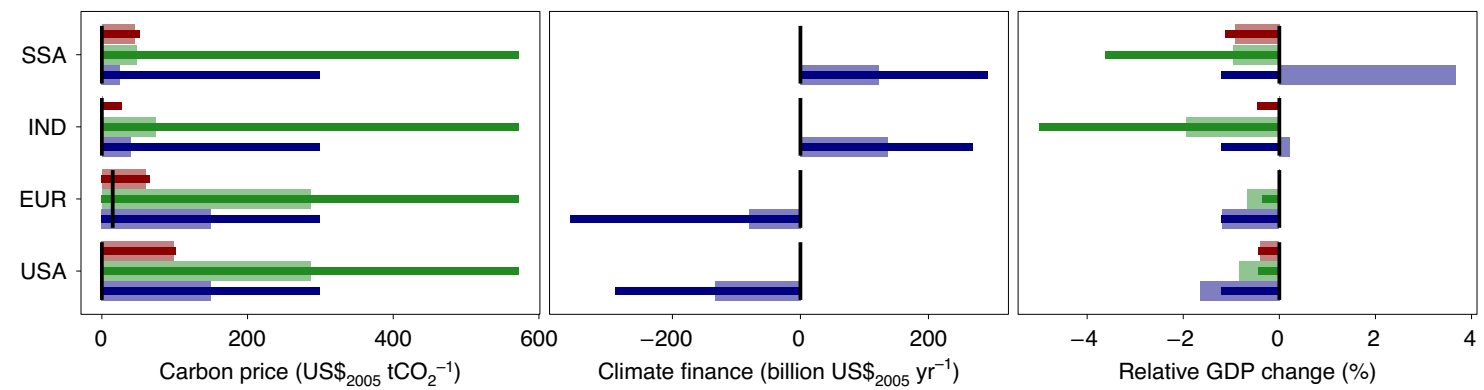

d

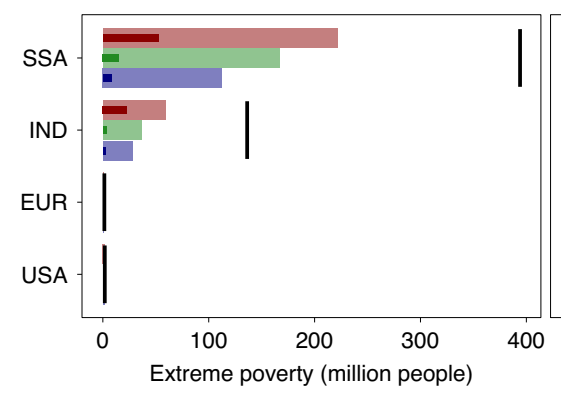

SDP-1.5C

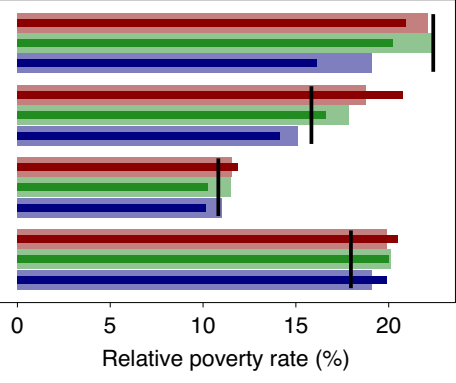

SSP2-NDC

SSP1-1.5C

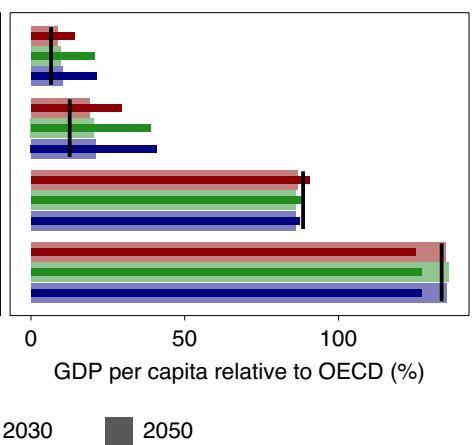

$2030 \quad 2050$

Fig. 4 | Regional outcomes for selected indicators resulting from the sustainable development interventions. Transparent wide bars represent 2030 values; solid thin bars are values for 2050. For comparison, the 2015 value is shown by the black line. We show the SSP2-NDC (red, top), SSP1-1.5C (green, centre) and SDP-1.5C (blue, bottom) scenarios; the SSP1-NDC scenario is omitted for reasons of visual clarity. a, Food: land-use-related emissions, nutrition and food expenditures. b. Energy: emissions from fossil fuels and industry (FFI), energy demand and energy expenditures. c, Climate policy and global cooperation: carbon price, international climate and development finance, and policy costs (change in GDP). d, Inequality and poverty: prevalence of extreme poverty, relative poverty rate, income convergence between regions. Regions are Sub-Saharan Africa (SSA), India (IND), European Union (EUR), United States (USA); selected to highlight the different sustainability challenges faced by low-to-middle-income and high-income regions, and the diversity within these groups. Extended Data Figs. 4 and 5 give additional indicators and regions.

Regional effects of interventions. We further show the effects of the interventions for selected regions (Fig. 4), illustrating how they create synergies and mitigate trade-offs between different SDGs. A more in-depth discussion of the land- and energy system dynamics is given in the Supplementary Information (section 4) and Extended Data Figs. 4 and 5.
The transition to a healthy and sustainable nutrition avoids an increase of food prices caused by climate policies. This leads to lower food expenditures especially in Sub-Saharan Africa (SSA) while increasing food availability (Fig. 4a). Agricultural $\mathrm{N}_{2} \mathrm{O}$ and $\mathrm{CH}_{4}$ emissions are drastically reduced across all regions, making it substantially easier to reach ambitious climate targets. Similarly, a 


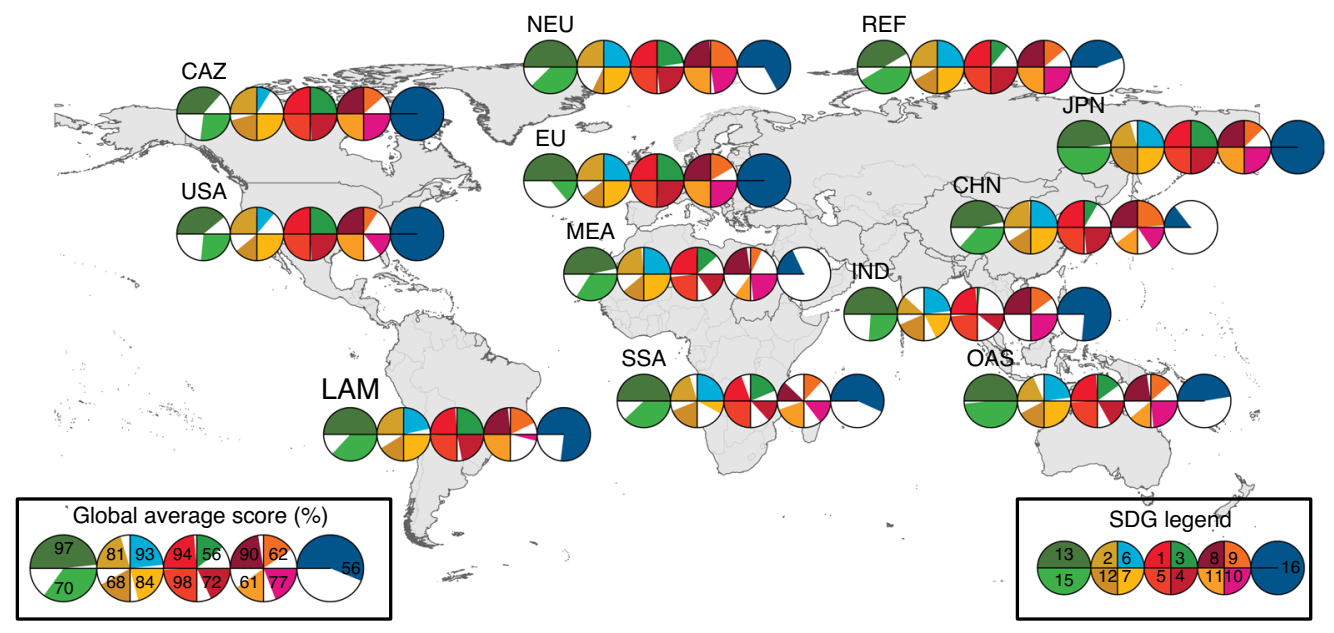

Fig. 5 | Regional SDG indicator scores in our SDP scenario in 2030. For each region, the five circles represent the five clusters-'planetary integrity', 'provision of material needs', 'people', 'prosperity' and 'political institutions' (left to right)-divided into segments according to the numbers of contained SDGs. The colour fill for each segment shows the regional score for the respective SDG headline indicator (Supplementary Table 1), with an empty segment corresponding to the worst regional value in 2015 (see Methods for details). Where required, we convert indicators to per-capita values or rates for comparability between regions (note that this differs from the global score in Fig. 3). For reference, we show at the bottom left an annotated version of the population-weighted global average score and an SDG legend at the bottom right. Solid grey lines delineate the geographical boundaries of model regions. Region codes are Canada/Australia/New Zealand (CAZ), China (CHN), European Union (EU), India (IND), Japan (JPN), Latin America and Caribbean (LAM), Middle East and North Africa (MEA), non-EU European countries (NEU), other Asian countries (OAS), Russia and former Soviet republics (reforming economies, REF), Sub-Saharan Africa (SSA) and the United States (USA).

transition away from energy-intensive lifestyles in industrialized countries (Fig. 4b) facilitates the decarbonization of energy supply. Taken together, this puts the $1.5^{\circ} \mathrm{C}$ target into reach with substantially lower carbon prices: we project around US\$150 per ton $\mathrm{CO}_{2}$ in 2030 for high-income regions and US $\$ 25$ per ton $\mathrm{CO}_{2}$ for SSA, around half the values of the SSP1-1.5C scenario. These lower prices reduce the risk of adverse policy side-effects, also making a comprehensive carbon pricing scheme easier to implement from a political economy perspective.

At the same time, SDG-compatible energy demands and rapid decarbonization can increase policy costs for developing regions, as for example reflected by the increased energy expenditure share in India in 2030 (Fig. 4b). However, these side-effects are more than compensated by an international 'climate and development' scheme financed partly from the carbon pricing revenues. The substantial financial inflows into developing regions (for example, US\$120 billion $\mathrm{yr}^{-1}$ for SSA in 2030) lead to near-term policy costs close to zero or even net policy gains (+3.7\% of GDP for SSA in 2030; Fig. 4c). These funds are used alongside the national carbon pricing revenues to finance poverty alleviation policies, resulting in substantial reductions in relative poverty (for example, -3.5 percentage points in SSA by 2030) and absolute poverty ( -55 million people compared to SSP1-1.5C; Fig. 4d).

Regional SDG achievement and gaps. The regional analysis of projected SDG achievement illustrates key geographical differences (Fig. 5). Lower-income regions still show substantial gaps in the 'provision', 'people' and 'prosperity' clusters in 2030, reflecting that even our optimistic SDP scenario does not fully overcome insufficient access to modern energy and poverty (particularly in SSA) as well as malnourishment until then (the last is by assumption eradicated until 2050). Furthermore, air pollution and its detrimental health effects remain at high levels, particularly in India. On the other hand, lower-income regions show mostly high scores in the 'planet' cluster, reflecting modest per-capita emissions, lower inorganic nitrogen fertilizer use and a more intact biosphere. For high-income regions we project mostly high scores in the 'provision', 'people' and 'prosperity' clusters, although with some exceptions (for example, high levels of inequality, agricultural water use and food waste in the United States). Most high-income regions, except for Japan, also show substantial gaps in the 'planet' cluster.

These results reflect that, when viewed through a multidimensional SDG lens, no country or region has fully achieved sustainability in 2030 but all need further development along certain dimensions. Importantly, however, both lower-income and high-income regions already substantially improve compared to the status quo ${ }^{51}$ until 2030 and for most indicators we project further progress until 2050 (Supplementary Information section 5 and Supplementary Fig. 22).

\section{Discussion}

Substantial progress towards many aspects of the Agenda 2030 is possible but it requires a combination of strong policy interventions across multiple dimensions together with ambitious lifestyle changes: healthy and sustainable diets drastically reduce non- $\mathrm{CO}_{2}$ GHG emissions, which increases the $1.5^{\circ} \mathrm{C}$-compatible $\mathrm{CO}_{2}$ budget and in turn limits carbon prices and policy costs (measured as relative GDP loss) despite higher, SDG-compatible energy demands in developing regions. Lower policy costs and a strongly reduced pressure on land limit the impact on energy and food expenditures, helping the poor to meet their needs. In addition, the national carbon pricing revenues and an ambitious international climate and development finance scheme provide funding for redistribution and poverty alleviation policies, especially in developing countries. Taken together, these interventions enable substantial progress along the social and developmental dimensions without further exacerbating environmental degradation. Nonetheless, a substantial gap towards the targets remains, mainly due to inertia in existing systems. However, the Paris Agreement and the SDGs remain guiding principles for longer-term sustainable development and we project that many of the persisting gaps can be closed by 2050 .

While our model-based SDP has a fairly comprehensive SDG coverage, we still only cover a subset of the full SDG space and many indicators are mapped to proxies. For example, we cover access to 
electricity and clean cooking only implicitly through useful energy per capita and address gender equality only through the gender education gap (which the official indicator set considers under SDG 4: education). A more explicit representation of SDG 5 indicators is challenging but needed in future studies. Also, our additional interventions do not cover all SDGs and, as such, certain indicators do not improve further between SSP1 and SDP (SDGs 4, 5, 8 and 16).

Although this framework provides a first step towards integrating governance factors (quality of political institutions and peace), we do not treat these factors endogenously yet. As an important next step, this would shed further light on their importance as preconditions (or also bottlenecks) for sustainable development.

A key modelling assumption is the linking between climate policies and poverty alleviation through the national and international redistribution of carbon pricing revenues ${ }^{52,53}$. Notably, this requires strong institutional capacity at both levels, and other beneficial uses of these revenues, such as education initiatives or infrastructure development ${ }^{54}$, are also possible. Furthermore, additional revenues for such development policies could be generated from other sources, such as bequest or land rent taxation.

We do not attempt to quantify the adverse effects of climate impacts on SDG outcomes ${ }^{55}$. As such, the residual impacts below the $1.5^{\circ} \mathrm{C}$ target and the benefits of mitigation policies through avoided impacts remain important steps for future research towards a truly integrated assessment of sustainable development outcomes.

Also, the detrimental effects of the COVID-19 pandemic ${ }^{56,57}$ are not yet captured in our modelling framework; thus, the gap towards certain SDGs will probably be larger in a post-pandemic world. While recovery packages to 'build back better' are a political opportunity to better align policies with climate action and the SDGs ${ }^{58,59}$, they also face an adverse environment of tightening fiscal spaces and increasing societal strain.

Despite these limitations, this comprehensive SDP scenario represents a pathway towards a more sustainable future. It demonstrates the possibility of moving towards the socioeconomic targets of the Agenda 2030, while at the same time respecting the Paris climate target and other key planetary boundaries. As such, it offers a vision of how to reconcile human well-being with planetary integrity.

\section{Online content}

Any methods, additional references, Nature Research reporting summaries, source data, extended data, supplementary information, acknowledgements, peer review information; details of author contributions and competing interests; and statements of data and code availability are available at https://doi.org/10.1038/ s41558-021-01098-3.

Received: 5 December 2020; Accepted: 11 June 2021; Published online: 2 August 2021

\section{References}

1. The Emissions Gap Report 2019 (UNEP, 2019).

2. Report of the Secretary-General on SDG Progress 2019 (United Nations, 2019).

3. Rogelj, J. et al. in Special Report on Global Warming of $1.5^{\circ} \mathrm{C}$ (eds Masson-Delmotte, V. et al.) Ch. 2 (WMO, 2018).

4. Zhenmin, L. \& Espinosa, P. Tackling climate change to accelerate sustainable development. Nat. Clim. Change 9, 494-496 (2019).

5. Sustainable development through climate action. Nat. Clim. Change $\mathbf{9}$, 491 (2019).

6. Pradhan, P., Costa, L., Rybski, D., Lucht, W. \& Kropp, J. P. A systematic study of sustainable development goal (SDG) interactions. Earths Future 5, 1169-1179 (2017).

7. McCollum, D. L. et al. Connecting the Sustainable Development Goals by their energy inter-linkages. Environ. Res. Lett. 13, 033006 (2018).

8. Transformations to Achieve the Sustainable Development Goals (IIASA, 2018); https://doi.org/10.22022/TNT/07-2018.15347

9. Sachs, J. D. et al. Six transformations to achieve the Sustainable Development Goals. Nat. Sustain. 2, 805-814 (2019).
10. van Soest, H. L. et al. Analysing interactions among Sustainable Development Goals with integrated assessment models. Glob. Transit. 1, 210-225 (2019).

11. Breuer, A., Janetschek, H. \& Malerba, D. Translating sustainable development goal (SDG) interdependencies into policy advice. Sustainability 11, 2092 (2019).

12. O'Neill, B. C. et al. Achievements and needs for the climate change scenario framework. Nat. Clim. Change 10, 1074-1084 (2020).

13. Moyer, J. D. \& Bohl, D. K. Alternative pathways to human development: assessing trade-offs and synergies in achieving the Sustainable Development Goals. Futures 105, 199-210 (2019).

14. von Stechow, C. et al. Integrating global climate change mitigation goals with other sustainability objectives: a synthesis-supplement. Annu. Rev. Environ. Resour. 40, 363-394 (2015).

15. Jakob, M. \& Steckel, J. C. Implications of climate change mitigation for sustainable development. Environ. Res. Lett. 11, 104010 (2016).

16. McCollum, D. L. et al. Energy investment needs for fulfilling the Paris Agreement and achieving the Sustainable Development Goals. Nat. Energy 3, 589-599 (2018)

17. Iyer, G. et al. Implications of sustainable development considerations for comparability across nationally determined contributions. Nat. Clim. Change 8, 124-129 (2018).

18. Fujimori, S. et al. Measuring the sustainable development implications of climate change mitigation. Environ. Res. Lett. 15, 085004 (2020).

19. Fuso Nerini, F. et al. Connecting climate action with other Sustainable Development Goals. Nat. Sustain. 2, 674-680 (2019).

20. Hof, C. et al. Bioenergy cropland expansion may offset positive effects of climate change mitigation for global vertebrate diversity. Proc. Natl Acad. Sci. USA 115, 13294-13299 (2018).

21. Stevanović, M. et al. Mitigation strategies for greenhouse gas emissions from agriculture and land-use change: consequences for food prices. Environ. Sci. Technol. 51, 365-374 (2017).

22. Fujimori, S. et al. A multi-model assessment of food security implications of climate change mitigation. Nat. Sustain. 2, 386-396 (2019).

23. Pachauri, S. et al. Pathways to achieve universal household access to modern energy by 2030. Environ. Res. Lett. 8, 024015 (2013).

24. Cameron, C. et al. Policy trade-offs between climate mitigation and clean cook-stove access in South Asia. Nat. Energy 1, 15010 (2016).

25. Humpenöder, F. et al. Large-scale bioenergy production: how to resolve sustainability trade-offs? Environ. Res. Lett. 13, 024011 (2018).

26. Bertram, C. et al. Targeted policies can compensate most of the increased sustainability risks in $1.5^{\circ} \mathrm{C}$ mitigation scenarios. Environ. Res. Lett. 13, 064038 (2018)

27. Tosun, J. \& Leininger, J. Governing the interlinkages between the Sustainable Development Goals: approaches to attain policy integration. Glob. Chall. 1, 1700036 (2017).

28. van Vuuren, D. P. et al. Pathways to achieve a set of ambitious global sustainability objectives by 2050: explorations using the IMAGE integrated assessment model. Technol. Forecast. Soc. Change 98, 303-323 (2015).

29. Liu, J.-Y. et al. The importance of socioeconomic conditions in mitigating climate change impacts and achieving Sustainable Development Goals. Environ. Res. Lett. 16, 014010 (2020).

30. van Vuuren, D. P. et al. Alternative pathways to the $1.5^{\circ} \mathrm{C}$ target reduce the need for negative emission technologies. Nat. Clim. Change 8 , 391-397 (2018).

31. Zimm, C., Sperling, F. \& Busch, S. Identifying sustainability and knowledge gaps in socio-economic pathways vis-à-vis the Sustainable Development Goals. Economies 6, 20 (2018)

32. van Vuuren, D. P. et al. Defining a sustainable development target space for 2030 and 2050. Preprint at EarthArxiv https://doi.org/10.31223/X5B62B (2021).

33. Riahi, K. et al. The Shared Socioeconomic Pathways and their energy, land use, and greenhouse gas emissions implications: an overview. Glob. Environ. Change 42, 153-168 (2017).

34. Grubler, A. et al. A low energy demand scenario for meeting the $1.5^{\circ} \mathrm{C}$ target and Sustainable Development Goals without negative emission technologies. Nat. Energy 3, 515-527 (2018).

35. Rogelj, J. et al. Scenarios towards limiting global mean temperature increase below $1.5^{\circ} \mathrm{C}$. Nat. Clim. Change 8, 325-332 (2018).

36. Willett, W. et al. Food in the anthropocene: the EAT-Lancet Commission on healthy diets from sustainable food systems. Lancet 393, 447-492 (2019).

37. Kriegler, E. et al. Fossil-fueled development (SSP5): an energy and resource intensive scenario for the 21 st century. Glob. Environ. Change 42, 297-315 (2017).

38. Steffen, W. et al. Planetary boundaries: guiding human development on a changing planet. Science 347, 1259855 (2015).

39. Rogelj, J., Forster, P. M., Kriegler, E., Smith, C. J. \& Séférian, R. Estimating and tracking the remaining carbon budget for stringent climate targets. Nature 571, 335-342 (2019). 
40. Hofmann, M. \& Schellnhuber, H. J. Ocean acidification: a millennial challenge. Energy Environ. Sci. 3, 1883-1896 (2010).

41. Gerten, D. et al. Feeding ten billion people is possible within four terrestrial planetary boundaries. Nat. Sustain. 3, 200-208 (2020)

42. Clark, M. A. et al. Global food system emissions could preclude achieving the $1.5^{\circ}$ and $2{ }^{\circ} \mathrm{C}$ climate change targets. Science 370 , 705-708 (2020).

43. Millward-Hopkins, J., Steinberger, J. K., Rao, N. D. \& Oswald, Y. Providing decent living with minimum energy: a global scenario. Glob. Environ. Change 65, 102168 (2020).

44. Madeddu, $\mathrm{S}$. et al. The $\mathrm{CO}_{2}$ reduction potential for the European industry via direct electrification of heat supply (power-to-heat). Environ. Res. Lett. 15, 124004 (2020)

45. Brundtland, G. et al. Our Common Future. Brundtland Report (Oxford Univ. Press, 1990).

46. Gómez-Sanabria, A. et al. Sustainable wastewater management in Indonesia's fish processing industry: bringing governance into scenario analysis. J. Environ. Manag. 275, 111241 (2020).

47. Acemoglu, D. \& Robinson, J. Why Nations Fail: The Origins of Power, Prosperity, and Poverty (Crown Publishers, 2012).

48. Coppedge, M. et al. V-Dem Codebook V10 (SSRN, 2020); https://doi. org/10.2139/ssrn.3557877

49. Sundberg, R. \& Melander, E. Introducing the UCDP Georeferenced Event Dataset. J. Peace Res. 50, 523-532 (2013).

50. Pettersson, T. \& Öberg, M. Organized violence, 1989-2019. J. Peace Res. 57, 597-613 (2020).
51. O’Neill, D. W., Fanning, A. L., Lamb, W. F. \& Steinberger, J. K. A good life for all within planetary boundaries. Nat. Sustain. 1, 88-95 (2018).

52. Fujimori, S., Hasegawa, T. \& Oshiro, K. An assessment of the potential of using carbon tax revenue to tackle poverty. Environ. Res. Lett. 15, 114063 (2020)

53. Soergel, B. et al. Combining ambitious climate policies with efforts to eradicate poverty. Nat. Commun. 12, 2342 (2021).

54. Franks, M., Lessmann, K., Jakob, M., Steckel, J. C. \& Edenhofer, O. Mobilizing domestic resources for the Agenda 2030 via carbon pricing. Nat. Sustain. 1, 350-357 (2018).

55. Byers, E. et al. Global exposure and vulnerability to multi-sector development and climate change hotspots. Environ. Res. Lett. 13, 055012 (2018).

56. Sachs, J. \& Schmidt-Traub, G. The Sustainable Development Goals and COVID-19 (Cambridge Univ. Press, 2020).

57. Naidoo, R. \& Fisher, B. Reset Sustainable Development Goals for a pandemic world. Nature 583, 198-201 (2020).

58. Hepburn, C., O'Callaghan, B., Stern, N., Stiglitz, J. \& Zenghelis, D. Will COVID-19 fiscal recovery packages accelerate or retard progress on climate change? Oxf. Rev. Econ. Policy 36, S359-S381 (2020).

59. Andrijevic, M., Schleussner, C.-F., Gidden, M. J., McCollum, D. L. \& Rogelj, J. COVID-19 recovery funds dwarf clean energy investment needs. Science 370, 298-300 (2020).

Publisher's note Springer Nature remains neutral with regard to jurisdictional claims in published maps and institutional affiliations.

(c) The Author(s), under exclusive licence to Springer Nature Limited 2021 


\section{Methods}

Overview and SDG indicator typology. Our modelling ecosystem is built around the integrated assessment modelling framework REMIND-MAgPIE. Both through extensions of the core framework and through the inclusion of additional downstream models, we substantially extend the coverage of the SDG space, leading to a total of 56 SDG indicators or proxies across all 17 SDGs. Broadly, the representation of these indicators in our modelling framework can be classified into four groups (Supplementary Table 1):

1. Exogenous scenario assumptions: our input data for population, labour productivity growth and educational attainment in the SDP scenario are taken from SSP1 (refs. ${ }^{60,61}$ ). The same holds true for the scenarios for the Gini coefficient ${ }^{62}$, which are used in the downstream model for inequality and poverty.

2. Demand projections: energy and food demand projections are derived with dedicated models and used as inputs in REMIND-MAgPIE. The demand projections for the SDP scenario are constructed to enable rapid progress towards SDG 2 and SDG7 by assuming sufficient nutrition and faster growth of per-capita energy demands in regions with currently low values (details below).

3. Endogenous results of REMIND-MAgPIE: GHG emissions, energy system characteristics and land-use patterns are direct results of the REMIND-MAgPIE optimization. Policy measures that enable or enhance progress towards the SDGs are implemented as parameter settings or constraints in the model (Supplementary Table 3). For example, we implement an additional coal phase-out policy that limits residual coal use in the SDP to values similar to the SSP1-1.5C scenario despite the lower carbon price.

4. Results from additional downstream models: climate and development finance is calculated as a postprocessing of the scenario results. The indicators for ocean, political institutions and conflict, inequality and poverty and air pollution are computed with dedicated models that take the scenario quantification by REMIND-MAgPIE as an input (details below).

For each SDG, we select one headline indicator (two for SDGs 13, 15 and 16) to be shown in the main figures. Headline indicators are selected with the aim to be representative of key aspects of the SDG, quantifiable in our modelling framework and with a quantitative target (note the exception for SDG 17). In many cases, our choice follows van Vuuren et al..$^{32}$; see also Supplementary Table 1. Results for the full set of indicators are shown in the Supplementary Information.

Scenario setup. Including our main SDP scenario we model four main scenarios that are chosen such that their comparison illustrates the effects of different interventions on SDG and climate outcomes.

- SSP2-NDC: socioeconomic development continues along a 'middle-of-the-road' pathway similar to recent historical trends. Energy, resource and food demands are largely determined by the growth of per-capita income levels, with no substantial break compared to historical trends. There is only weak climate policy according to the current NDC pledges until 2030 and with a corresponding level of regional ambition thereafter (Supplementary Information section 6.2 and Supplementary Fig. 23).

- SSP1-NDC: socioeconomic development follows a more optimistic pathway with higher GDP and lower population growth, also as a consequence of policy interventions in the areas of education and gender equality (intervention A). There is a general trend towards higher resource efficiency and environmentally more conscious lifestyles, which reduces overall energy and material demands (intervention B). Note, however, that interventions A and B are not resolved via explicit policy measures-instead we capture them through adapting model inputs appropriately ${ }^{33,37}$ (reflecting the outcome of the policy measures). Climate policy follows the NDCs and their extrapolation (as in SSP2-NDC).

- SSP1-1.5C: the socioeconomic trends of the SSP1-NDC scenario are supplemented with an ambitious climate policy consistent with the $1.5^{\circ} \mathrm{C}$ target from the Paris Agreement (intervention C).

- SDP-1.5C: for our SDP scenario, which represents the main innovation of this study, additional sustainable development policies in the area of global cooperation, national redistribution, healthy and sustainable nutrition, energy access, as well as further sustainability policies for the energy and land-use systems are added (interventions D-F). Baseline GDP and population are identical to the SSP1-based scenarios, energy and food demands are projected separately (details below). On the supply side of intervention D (both land and energy), several of the sustainability policies follow Bertram et al. ${ }^{26}$. Additional policies introduced in this study include a coal phase-out policy (differentiated by income level), as well as a protection of biodiversity hotspots. A detailed comparison of the modelling assumptions for the different scenarios is given in Supplementary Tables 2 and 3.

Furthermore, we use the following auxiliary scenarios as reference cases or for additional analysis:

- SSP2-NPi: this 'national policies implemented' scenario uses the same baseline assumptions as the SSP2-NDC scenario but only includes already implemented climate policies (as opposed to intended future policies) ${ }^{63}$. We use it as a reference case for calculating policy costs (for example, GDP loss due to mitigation policies) for the SSP2-based scenarios.
- $\quad$ SSP1-NPi: same as SSP2-NPi but for SSP1-based scenarios.

- SDP-NPi: same as SSP2-NPi but for SDP scenario.

- SSP2-1.5C: this scenario starts from the same baseline as the SSP2-NDC scenario and implements only ambitious climate policies without any extra sustainability policies. It is not used in the main scenario cascade shown in this study but only for additional analysis and visualizations (Supplementary Information).

- SSP1/SDP 'hybrid' scenarios: for an additional decomposition analysis (Extended Data Fig. 3), we have simulated scenarios with an SDP parameterization on the energy (REMIND) and SSP1 parameterization on the land (MAgPIE) side and vice versa. Further details are given in the Supplementary Information (section 3).

Climate policy. We implement ambitious climate policies as a not-to-exceed (peak) budget ${ }^{64}$ for $\mathrm{CO}_{2}$ emissions consistent with the $1.5^{\circ} \mathrm{C}$ target. Using a peak budget instead of the end-of-century budgets often used in previous integrated assessment model (IAM) scenario studies allows for a more direct link between $\mathrm{CO}_{2}$ budget and temperature at peak warming and limits the possibility to compensate for continued high emissions in the near-term with large amounts of $\mathrm{CO}_{2}$ removal later.

For the SSP1-1.5C and SSP2-1.5C scenarios, we use a peak budget of $900 \mathrm{GtCO}_{2}$ (counting from 2011 onwards; that is, around $610 \mathrm{GtCO}_{2}$ from 2018 onwards), consistent with limiting warming to $1.5^{\circ} \mathrm{C}$ with low overshoot $\left(<0.1^{\circ} \mathrm{C}\right.$; ref. $\left.^{3}\right)$ at median warming response ${ }^{65}$. However, these two scenarios still use around $200 \mathrm{Gt}$ of net-negative $\mathrm{CO}_{2}$ emissions in the second half of the century to reduce warming to below $1.5^{\circ} \mathrm{C}$ with at least $67 \%$ likelihood by 2100 . For our SDP scenario, the transition to healthy and sustainable diets substantially reduces land-use-related emissions of non- $\mathrm{CO}_{2}$ GHGs such as methane and nitrous oxide. Therefore the $\mathrm{CO}_{2}$ peak budget compatible with the $1.5^{\circ} \mathrm{C}$ target increases ${ }^{39}$ by 100 Gt to $1,000 \mathrm{GtCO}_{2}$ from 2011 onwards and the need for net-negative $\mathrm{CO}_{2}$ emissions is substantially reduced (more detailed results are given in the discussion of SDG 13 in the Supplementary Information).

For the implementation of the peak budget, we assume that $\mathrm{CO}_{2}$ prices in high-income regions increase linearly until the budget is reached, while lower-income regions initially face substantially lower prices (details below). Linearly increasing $\mathrm{CO}_{2}$ prices, in contrast to the more common exponentially rising $\mathrm{CO}_{2}$ prices with a growth rate equalling the social discount rate, increase the near-term ambition of climate policy but limit the price increases at a later stage. Both the optimal peak year and the required $\mathrm{CO}_{2}$ price in this year are determined endogenously through an iterative algorithm, thus determining the rate of increase of the $\mathrm{CO}_{2}$ price before the peak year ${ }^{6}$. After the peak budget has been reached, the $\mathrm{CO}_{2}$ price increase flattens off to US $\$ 3$ per ton $\mathrm{CO}_{2}$ per $\mathrm{yr}$, which is sufficient to ensure that the GMT increase declines from its peak to values consistent with the $1.5^{\circ} \mathrm{C}$ target with at least $67 \%$ probability by the end of the century. Non- $\mathrm{CO}_{2}$ GHGs are priced according to their 100-yr global warming potentials (using IPCC Fifth Assessment Report values), where in the land-use sector prices for $\mathrm{CH}_{4}$ and $\mathrm{N}_{2} \mathrm{O}$ are capped once further price increases no longer provide additional abatement options ${ }^{67}$.

We further implement a regional differentiation of carbon prices until mid-century to model a period of staged accession: in high-income regions, the $\mathrm{CO}_{2}$ price follows the trajectory described above. Lower- and middle-income regions, on the other hand, initially face substantially lower prices, where the respective reduction factor is assigned according to their GDP (PPP) per capita values in 2015. We assume that the reduction factor converges to unity following a convex trajectory; from 2050 onwards a globally uniform carbon price is used. An overview of the resulting regional carbon prices for the different mitigation scenarios is given in Supplementary Fig. 23.

This level of differentiation represents an intermediate case between a globally uniform carbon price and the substantially higher degree of differentiation required to equalize mitigation costs as a fraction of GDP between countries without any international transfers ${ }^{6}$. The differentiated carbon prices also form one of the components of our burden-sharing scheme; see below for a description of the other building blocks.

Burden sharing and climate and development finance. In contrast to previous studies on sustainable pathways, we explicitly address the question of equitably sharing the mitigation burden, as well as the global effort of meeting the SDGs.

To this end, we implement an ambitious 'climate and development' scheme that shares the mitigation effort and provides additional funding for development policies. In addition to the staged accession to climate policy (description above), the scheme consists of the following two components:

1. International redistribution of carbon pricing revenues: one-third of the energy sector GHG pricing revenues from each region are paid into an international scheme. Payouts from the scheme are distributed to regions proportionally to their population shares and their GDP per-capita gap to the richest region. The scheme is gradually introduced until 2030 and then phases out over time as emissions, and therefore also carbon pricing revenues, reduce to near-zero around mid-century. 
2. Equal-effort burden sharing in the long term: in addition to this partial redistribution of revenues, we assume a transition to an equal-effort burden-sharing scheme ${ }^{69}$. Additional interregional climate and development finance transfers are calculated such that relative GDP losses (calculated with respect to the respective NPi scenario) are equalized between regions from 2050 onwards. This provides additional financial inflows to developing regions also beyond the time of net carbon neutrality, to compensate for their substantially higher relative policy costs than high-income regions ${ }^{68,70,71}$. The scheme is gradually introduced between 2020 and 2050, thus reaching its full effect at the same time when the convergence to a globally uniform carbon price is completed.

We show the international financial transfers implied by this scheme and a comparison of relative policy costs across the scenarios in the discussion of SDG 17 in Supplementary Fig. 17. Importantly, the climate and development finance transfers emerging from this scheme are used as additional funds for redistribution and poverty alleviation policies ${ }^{52,53}$ in the form of a universal cash $\operatorname{transfer}^{72}$ (for example, around US $\$ 100 \mathrm{cap}^{-1} \mathrm{yr}^{-1}$ for SSA in 2030; see also the model description 'Inequality and poverty' below)

Compared to previous burden-sharing schemes discussed in the literature (for example, refs. ${ }^{69-71}$ ), our approach does not combine a uniform global carbon price with transfers between regions via trading of regional emissions allowances on a global carbon market. Instead, we combine differentiated carbon prices with international climate and development finance transfers ${ }^{68}$. This mixed policy approach honours the principle of common but differentiated responsibility, as well as objectives of equity and sustainable development: a key underlying principle of our approach is that climate change mitigation should not deepen existing socioeconomic inequalities but should improve the development prospects of the Global South (see also the Greenhouse Development Rights framework $^{73}$ ). Recognizing that meeting the SDG agenda is a global challenge, our burden-sharing scheme understands carbon pricing and an international redistribution of part of its revenues, as an important source of funding for fostering sustainable development.

Regional SDG achievement gap analysis. Figure 5 displays a regional analysis of SDG achievements in 2030; here we detail the methodology of this analysis. We start from our headline indicator set but exclude indicators without quantified targets (the climate finance indicator for SDG 17), as well as indicators only available at the global level (GMT increase, ocean acidification and conflict fatalities). As a consequence, the clusters 'planetary integrity' and 'political institutions, peace and partnership' contain only two and one SDG, respectively, whereas all other clusters contain four SDGs.

For each indicator, we set the zero line at the worst regional value in 2015; note that this differs from the global gap analysis in Fig. 3, where the global value in 2015 forms the zero line. This approach takes into account if regions already perform well for a given indicator, instead of evaluating only whether a small remaining gap is fully closed (for example, reducing extreme poverty from a value marginally above zero to exactly zero in high-income countries). A similar metric is used for the SDG index by the Sustainable Development Report ${ }^{56}$.

For each indicator we then compute the SDG achievement score using the targets from Supplementary Table 1. Several indicators are extensive quantities; for these we perform the regional analysis on a per-capita basis. Using the example of GHG emissions, this corresponds to comparing regional per-capita emissions to the global per-capita target value. Similarly, for SDG 1, we compare poverty rates rather than absolute values between regions. (Note that this again differs from the global analysis in Fig. 3 where global aggregate values or headcounts were used. As a consequence, the global average score displayed in Fig. 5 differs from the values shown in Fig. 3.) For SDG 8 (income convergence) targets are differentiated by region $^{32}$, while for all other SDGs targets are the same across regions. SDG 15 is represented by two indicators; here, we averaged the two scores for biodiversity intactness and nitrogen fixation.

Model descriptions. Our integrated modelling framework consists of multiple models, with the IAM framework REMIND-MAgPIE at its core and multiple additional models linked to it (Extended Data Fig. 2). Here, we provide brief descriptions of the individual models and their linking.

REMIND-MAgPIE IAM framework. The REMIND-MAgPIE framework ${ }^{37,74,75}$ consists of a multiregional energy-economy-climate model (REMIND; refs. ${ }^{66,76}$ ) coupled to a spatially explicit land-system model (MAgPIE; ref. ${ }^{77}$ ). The framework integrates the simple climate model MAGICC (ref. ${ }^{65}$ ) and takes up biophysical information from the vegetation and hydrology model LPJmL (ref. ${ }^{78}$ ) (details below). Both REMIND and MAgPIE are available open source together with extensive documentation (see references in next sentence). For this work, a model version close-to-identical to v.2.1.3 (REMIND) ${ }^{79,80}$ and model v.4.2.1 (MAgPIE) ${ }^{81,82}$ were used (Code availability).

REMIND (regional model of investments and development) models the global economy and energy system with 12 world regions, where large economies are resolved individually and smaller economies are grouped into model regions. The macro-economy of every region is modelled using a Ramsey growth model with a production function with constant elasticity of substitution. The main production factors are capital, labour and energy, where through the last the macro-economic core is hard-linked to a detailed representation of the energy system covering all major primary energy carriers, conversion technologies and end-use sectors. Regions are first solved individually by maximizing intertemporal regional welfare; the global solution is found by iteratively adjusting market prices for primary energy carriers and the composite good and updating the regional solutions until all markets are cleared. Emissions of all major GHGs are tracked in REMIND; the corresponding GHG concentrations, radiative forcing levels and the increase in GMT are calculated with the simple climate model MAGICC (ref. ${ }^{65}$; v.6, deterministic setup).

MAgPIE (model of agricultural production and its impact on the environment) describes the global land-use system using an economic partial-equilibrium approach with the same 12 model regions as REMIND. Agricultural production is subject to spatially explicit (clustered from $0.5^{\circ}$ resolution cells ${ }^{83}$ ) biophysical constraints such as water availability and yield patterns, which are in turn derived from the vegetation and hydrology model LPJmL ${ }^{78}$. All major crop and livestock product types are represented, as well as supply chain losses and demand for non-food agricultural goods. The model simulates a detailed representation of the agricultural nitrogen cycle using mass balance approaches that estimate inorganic fertilization requirements on the basis of harvest quantities, the availability of organic fertilizers and a trajectory for nitrogen uptake efficiency ${ }^{84,85}$. Carbon stocks of vegetation and soils are estimated using the LPJmL model and are affected by land-cover changes ${ }^{86}$. On the basis of a representation of carbon stocks and the nitrogen cycle, the emissions associated with land use and agricultural production are calculated.

In MAgPIE, land-use change impacts on terrestrial biodiversity are assessed via the BII (refs. ${ }^{87,88}$ ). The BII accounts for net changes in the abundance of organisms in relation to human land-use and age class of natural vegetation. Changes are then expressed relative to a reference land-use class, for which primary vegetation (forested or non-forested) is used and are weighted by a spatially explicit range-rarity layer ${ }^{89}$. Primary vegetation and mature secondary vegetation have a BII of 1, while other land-cover classes, such as cropland (0.5-0.7), have lower BII values.

In the coupled REMIND-MAgPIE framework ${ }^{37,74,75}$ the two models are run iteratively: The information on GHG pricing and bioenergy demand (REMIND) and land-use-related emissions and bioenergy prices (MAgPIE) are updated in turn after each individual model run until a joint equilibrium is achieved. This soft-coupled framework allows for a higher degree of process detail in the two individual models, while the solution converges to the one of a single joint optimization problem.

Energy demand projections. The energy demands for the industry, transport and residential and commercial sectors in REMIND are determined endogenously. The model can respond to climate policies with a demand reduction by switching to more efficient technologies (for example, from internal combustion engines to battery electric vehicles). However, the relation between energy demands and economic output is inferred from a calibration phase ${ }^{66}$. The input trajectories for this calibration, representing the energy demands in the absence of climate policies (details in Supplementary Information), are calculated with the EDGE (Energy Demand Generator) model suite based on GDP per capita and cost trends and additional scenario assumptions ${ }^{66,90}$. Our SSP1 and SSP2 scenarios use existing EDGE parameterizations; for the SDP scenario, we develop new final energy demand pathways that better reflect the SDG ambition of satisfying energy needs for decent living ${ }^{43,91,92}$ especially in low-income countries. At the same time, we include ambitious reductions of energy demands in high-income countries, which are driven by a shift towards less energy-intensive lifestyles as well as increases in energy efficiency (Extended Data Fig. 5 and Supplementary Fig. 24).

For the industry sector, we start from the lower value of the existing SSP1 and SSP2 trajectories but apply an additional GDP-per-capita-dependent factor to the rate of change of energy intensity. Parameter values are chosen to allow for an increase of final energy (FE) demands in lower-income regions to reflect the additional energy demand for infrastructure buildup ${ }^{91}$. In middle- and higher-income regions, demands are reduced substantially (Supplementary Fig. 24, left panel). Besides improvements in energy efficiency, this also requires substantial reductions in material demands and recycling of energy-intensive materials such as steel ${ }^{93}$.

In the transport sector, the guiding principle is a gradual convergence to a provision of an equal amount of useful (that is, motive) energy per capita across regions. We assume targets of $\sim 2 \mathrm{GJ} \mathrm{cap}^{-1} \mathrm{yr}^{-1}$ for passenger transport and $1.5 \mathrm{GJ} \mathrm{cap}^{-1} \mathrm{yr}^{-1}$ for freight transport, in line with recent estimates of decent living energy requirements ${ }^{43,92}$. The resulting trajectories are presented in the right panel of Supplementary Fig. 24, showing a range of 4-10 GJ cap $^{-1} \mathrm{yr}^{-1}$ in 2050 across regions.

Energy demands for residential and commercial buildings are derived using the EDGE-Buildings model ${ }^{90,94}$. Our SDP trajectory for per-capita final energy use in buildings (Supplementary Fig. 24, central panel) is based on the 'low' scenario assumptions from Levesque et al. ${ }^{94}$, which combines technological and lifestyle developments leading to low energy consumption patterns. These assumptions 
are applied to the SSP1 socioeconomic dynamics but are augmented by an even faster transition to modern energy carriers in developing regions than in the SSP1 scenario. We note that, in particular, the replacement of traditional biomass as a cooking fuel with modern appliances (for example, electricity and liquefied petroleum gas) can lead to a temporary reduction of cooking final energy demand. At the same time, UE continues to increase, as modern technologies have vastly superior FE-to-UE conversion efficiencies.

Food demand projections. Food demand scenarios for the SSP1 and SSP2 scenarios are based on a food demand model with population growth, change of demographic structure and per-capita income as main drivers ${ }^{95}$. The model combines anthropometric and econometric approaches to estimate the distribution of underweight, overweight and obesity, as well as body height by country, age-cohort and sex. It furthermore estimates food intake and food waste, as well as the dietary composition between four major food items: animal-source calories, empty calories, calories from fruits, vegetables and nuts, as well as staple calories. All elasticity parameters within the model are estimated on the basis of past observed data. To account for less material-intensive consumption patterns in the SSP1 storyline, food waste and dietary composition patterns are estimated on the basis of different functional forms than in the SSP2 scenario, assuming lower food waste, animal calories and processed foods and higher consumption of fruits, vegetables, nuts and staples. For the SDP scenario, we assume a gradual transition to the dietary patterns proposed by the EAT-Lancet Commission ${ }^{36}$ by 2050 (that is, to both healthy and sustainable diets with low food waste). Total food intake is still estimated on the basis of the anthropometric equations of the food demand model but taking into account the assumption of a healthy body weight.

Our food demand model accounts for the reduction of real per-capita income due to rising food prices and for a reduction of intake and a change of food composition when real income falls (note, however, that distributional aspects are not included yet). Under the food price effects of climate policies, we find only a small impact on the prevalence of underweight, even in the absence of additional sustainability policies (Fig. 2). The reason for this is that our empirically estimated income-elasticities of underweight and food intake ${ }^{95}$ are rather low compared to other models that often work with food expenditure elasticities ${ }^{96}$. Moreover, we only consider the income effect and not the substitution effect of the price shock. The income effect should, however, be the dominant effect for low-income households given that food is an existential need.

Additional models for SDG indicators. Inequality and poverty. We calculate projections for the income inequality and poverty indicators at the country level following the approach of Soergel et al. ${ }^{53}$. Starting from a baseline income distribution with a level of inequality determined by the Gini projections for the $\mathrm{SSPs}^{62}$, changes to the distribution due to climate policy are determined by the aggregate GDP loss, increased energy and food expenditures and the recycling of carbon pricing revenues. Importantly, this captures the potentially regressive effects of food and energy price increases, as well as the progressive effect of revenue recycling policies. For the SDP scenario we assume that revenues (including net transfer revenues) are redistributed on an equal-per-capita basis. While more targeted redistribution schemes are conceivable, they also face a number of difficulties in practice ${ }^{97}$ and therefore we do not implement them here (see also the discussion in Soergel et al. $\left.{ }^{53}\right)$. For the other mitigation scenarios, revenues are recycled without progressive redistribution policies (that is, without changing the level of inequality).

We calculate poverty rates for three poverty thresholds (US $\$ 1.90 \mathrm{~d}^{-1}$, US $\$ 3.20 \mathrm{~d}^{-1}$ and US $\$ 5.50 \mathrm{~d}^{-1}$; in PPP 2011) using a regression model fit to recent World Bank poverty data. For the purpose of this paper, we extend the model to additionally calculate the relative poverty rate (defined at the country level as the fraction of the population below $50 \%$ of the national median income) and the income of the bottom $40 \%$ relative to the national average directly from the income distribution and subsequently aggregate them from national to regional and global level using a population-weighted average.

Note that the inequality and poverty indicators are calculated in postprocessing (that is, we do not feed the results back into the models for energy or food demand). Despite the known differences in consumption patterns between rich and poor households, we do not expect the changes in poverty rates to affect the environmental pressures in a substantial way (see also Hubacek et al..$^{98}$ ).

Political institutions and violent conflict. These factors have not been modelled by earlier IAM-based scenario analyses, leaving it largely unclear which implicit trajectories are consistent with or even required by such scenarios. More generally, this reflects a lack of integration of governance and conflict research and IAM-based scenario studies. As a first step towards a more comprehensive integration in models, we calculate projections for the quality of political institutions and fatalities from armed conflict using linear fixed-effects regression models (Supplementary Information methods for SDG 16 gives a complete description). This quantifies the trajectories which are implied by the exogenous scenario assumptions (education, population and GDP). We include the endogenous effects of mitigation costs and international transfers on GDP per capita (details below), thus extending earlier work on governance and conflict likelihood in the SSP baselines ${ }^{99,100}$. In comparison to these earlier works, we also focus on different indicators, which better capture variation in conflict intensity and more closely measure the individual governance-related goals of SDG 16

We estimate both models using country-year data for all relevant indicators from 1995 to 2015. The institution model estimates the yearly change in the strength and quality of rule of law and civil liberties. The model takes as predictors the quality of rule of law and civil liberties and change in the quality of rule of law and civil liberties in the previous year, GDP per-capita growth, the share of men without primary education, the gender gap in primary education and the population growth. The conflict model estimates the change in fatalities in a country and is based on the following predictors: conflict fatalities and the change of conflict fatalities in the previous year, population growth, GDP per-capita growth and the number of men without primary education. Earlier models on economic development and governance assumed that unobserved differences between countries partially converge ${ }^{101,102}$. To account for different scenario-specific global convergence, we follow this practice in both models.

We note that SDP and SSP1 projections are very similar because they share several identical drivers (education and population). While GDP per capita slightly varies between these scenarios due to mitigation costs and international transfers, this does not substantially change the institution and conflict outcomes given the estimated regression coefficient for GDP per capita. Furthermore, explicitly modelling feedback loops to other goals is beyond the scope of this analysis but is an important avenue for future research.

Air pollution. We model the whole source-receptor relationship of air pollution-induced health impacts; see Rauner et al. ${ }^{103}$ for an extended description of the method. The model chain starts with aggregated emission factors, capturing pollution control policies as well as technology research, development, deployment and diffusion derived from the GAINS (GHG-air pollution interactions and synergies) model ${ }^{104}$. The simplified air chemistry model TM5-FAAST ${ }^{105}$ translates emissions into yearly average concentrations. Using spatially explicit data on demographics and urbanization allows the calculation of exposure level and disease-specific disability adjusted life years lost. The urban air pollution concentration is calculated by an urban-population-weighted average of the concentration in each spatial grid cell $\left(0.1^{\circ} \times 0.1^{\circ}\right)$.

Ocean model description and experimental design. CLIMBER-3alpha $+\mathrm{C}$, an Earth system model of intermediate complexity (EMIC), comprises individual and interactively coupled submodels of the atmosphere, the ocean and the sea ice ${ }^{106}$. The statistical-dynamical atmosphere model almost realistically reproduces the large-scale features of patterns of wind, precipitation and temperature. The two-dimensional dynamic-thermodynamic sea-ice model ${ }^{107}$ is based on the theory of the elasto-viscous-plastic rheology. A fully three-dimensional coarse resolution ocean general circulation model—an improved version of MOM3 (refs. ${ }^{108,109}$ )— computes the large-scale ocean dynamics including temperature and salinity distributions, an indispensable prerequisite when attempting to simulate marine biogeochemical processes. The latter are based on an extended and improved version of the Hamburg Ocean Carbon Cycle Model v.3.1 (HAMOCC3.1; ref. ${ }^{110}$ ) which was recently dubbed ' $+\mathrm{C}$ ' (ref. ${ }^{111}$ ).

After running the model into a steady state under pre-industrial boundary conditions (spin-up), it is integrated over a time period of $350 \mathrm{yrs}$ by imposing anthropogenic GHG emissions. From 1800 to 2004, the model is forced by historical $\mathrm{CO}_{2}$ emissions, subsequently continuing until 2150 by using the model output from the corresponding REMIND scenarios. CLIMBER-3alpha $+\mathrm{C}$ does not account for the effects of non- $\mathrm{CO}_{2} \mathrm{GHG}$, such as methane and nitrous oxide. Therefore, we have added the additional radiative forcing caused by these gases to CLIMBER-3alpha $+\mathrm{C}$ by using the output of the simple climate model MAGICC.

Reporting Summary. Further information on research design is available in the Nature Research Reporting Summary linked to this article.

\section{Data availability}

The data and analysis scripts supporting the findings of this study ${ }^{112}$ are available at https://doi.org/10.5281/zenodo.4787613. The following publicly accessible datasets were used for the institutional quality and conflict fatalities models (Supplementary Information references): Varieties of Democracy (V-Dem) (Country-Year/Country-Data) Dataset v.10, the Uppsala Conflict Data Program (UCDP) Georeferenced Event Dataset (GED) Global v.20.1 and Population and Human Capital Stocks data by the Wittgenstein Centre. They can be accessed via the following links: https://www.v-dem.net/en/data/archive/ previous-data/v-dem-dataset/; https://ucdp.uu.se/downloads/; http://dataexplorer. wittgensteincentre.org/wcde-v2/

\section{Code availability}

Both REMIND and MAgPIE are available open source under the following links: REMIND: https://github.com/remindmodel/remind; MAgPIE: https:// github.com/magpiemodel/magpie. The exact model versions used are: REMIND: https://github.com/bs538/remind/tree/SDP_runs; MAgPIE: https://github.com/ magpiemodel/magpie/releases/tag/v4.2.1 


\section{References}

60. Kc, S. \& Lutz, W. The human core of the shared socioeconomic pathways: population scenarios by age, sex and level of education for all countries to 2100. Glob. Environ. Change 42, 181-192 (2017).

61. Dellink, R., Chateau, J., Lanzi, E. \& Magné, B. Long-term economic growth projections in the Shared Socioeconomic Pathways. Glob. Environ. Change 42, 200-214 (2017).

62. Rao, N. D., Sauer, P., Gidden, M. \& Riahi, K. Income inequality projections for the Shared Socioeconomic Pathways (SSPs). Futures 105, 27-39 (2018)

63. Roelfsema, M. et al. Taking stock of national climate policies to evaluate implementation of the Paris Agreement. Nat. Commun. 11, 2096 (2020).

64. Rogelj, J. et al. A new scenario logic for the Paris Agreement long-term temperature goal. Nature 573, 357-363 (2019).

65. Meinshausen, M., Raper, S. C. B. \& Wigley, T. M. L. Emulating coupled atmosphere-ocean and carbon cycle models with a simpler model, MAGICC6-Part 1: Model description and calibration. Atmos. Chem. Phys. 11, 1417-1456 (2011).

66. Baumstark, L. et al. REMIND2.1: transformation and innovation dynamics of the energy-economic system within climate and sustainability limits. Preprint at Geosci. Model Dev. Discuss. https://doi.org/10.5194/gmd-2021-85 (2021).

67. Lucas, P. L., van Vuuren, D. P., Olivier, J. G. J. \& den Elzen, M. G. J. Long-term reduction potential of non- $\mathrm{CO}_{2}$ greenhouse gases. Environ. Sci. Policy 10, 85-103 (2007).

68. Bauer, N. et al. Quantification of an efficiency-sovereignty trade-off in climate policy. Nature 588, 261-266 (2020).

69. Höhne, N., den Elzen, M. \& Escalante, D. Regional GHG reduction targets based on effort sharing: a comparison of studies. Clim. Policy 14, 122-147 (2014).

70. Tavoni, M. et al. Post-2020 climate agreements in the major economies assessed in the light of global models. Nat. Clim. Change 5, 119-126 (2015).

71. Leimbach, M. \& Giannousakis, A. Burden sharing of climate change mitigation: global and regional challenges under shared socio-economic pathways. Climatic Change 155, 273-291 (2019).

72. Banerjee, A., Niehaus, P. \& Suri, T. Universal Basic Income in the Developing World (NBER, 2019); https://www.nber.org/papers/w25598

73. Baer, P., Athanasiou, T. \& Kartha, S. The Greenhouse Development Rights Framework: The Right to Development in a Climate Constrained World 2nd edn (Heinrich Böll Foundation, Christian Aid, EcoEquity and the Stockholm Environment Institute, 2008).

74. Klein, D. et al. The value of bioenergy in low stabilization scenarios: an assessment using REMIND-MAgPIE. Climatic Change 123, 705-718 (2014).

75. Bauer, N. et al. Bio-energy and $\mathrm{CO}_{2}$ emission reductions: an integrated land-use and energy sector perspective. Climatic Change 163, 1675-1693 (2020).

76. Luderer, G. et al. Description of the REMIND Model (Version 1.6) (PIK, 2015); https://www.pik-potsdam.de/en/institute/departments/transformationpathways/models/remind/remind16 description_2015_11_30 final

77. Dietrich, J. P. et al. MAgPIE 4-a modular open-source framework for modeling global land systems. Geosci. Model Dev. 12, 1299-1317 (2019).

78. Schaphoff, S. et al. LPJmL4-a dynamic global vegetation model with managed land - Part 1: model description. Geosci. Model Dev. 11, 1343-1375 (2018).

79. Luderer, G. et al. REMIND-REgional Model of INvestments and Development (Zenodo, 2020); https://doi.org/10.5281/zenodo.4091409

80. REMIND-REgional Model of INvestments and Development-Overview (Potsdam Institute for Climate Impact Research, 2020); https://rse. pik-potsdam.de/doc/remind/2.1.3/

81. Dietrich, J. P. et al. MAgPIE-An Open Source Land-use Modeling Framework (Zenodo, 2020); https://doi.org/10.5281/zenodo.3829896

82. MAgPIE-An Open Source Land-use Modeling Framework 4.2.1 (Potsdam Institute for Climate Impact Research, 2020); https://rse.pik-potsdam.de/ doc/magpie/4.2.1/

83. Dietrich, J. P., Popp, A. \& Lotze-Campen, H. Reducing the loss of information and gaining accuracy with clustering methods in a global land-use model. Ecol. Model. 263, 233-243 (2013).

84. Bodirsky, B. L. et al. $\mathrm{N}_{2} \mathrm{O}$ emissions from the global agricultural nitrogen cycle-current state and future scenarios. Biogeosciences $\mathbf{9}$, 4169-4197 (2012).

85. Bodirsky, B. L. et al. Reactive nitrogen requirements to feed the world in 2050 and potential to mitigate nitrogen pollution. Nat. Commun. $\mathbf{5}$ 3858 (2014).

86. Popp, A. et al. Land-use protection for climate change mitigation. Nat. Clim. Change 4, 1095-1098 (2014).

87. Scholes, R. J. \& Biggs, R. A biodiversity intactness index. Nature 434, 45-49 (2005).

88. Purvis, A. et al. in Advances in Ecological Research (eds Bohan, D. A. et al.) 201-241 (Academic Press, 2018).
89. Leclère, D. et al. Bending the curve of terrestrial biodiversity needs an integrated strategy. Nature 585, 551-556 (2020).

90. Levesque, A. et al. How much energy will buildings consume in 2100 ? A global perspective within a scenario framework. Energy 148, 514-527 (2018).

91. Steckel, J. C., Brecha, R. J., Jakob, M., Strefler, J. \& Luderer, G. Development without energy? Assessing future scenarios of energy consumption in developing countries. Ecol. Econ. 90, 53-67 (2013).

92. Rao, N. D., Min, J. \& Mastrucci, A. Energy requirements for decent living in India, Brazil and South Africa. Nat. Energy 4, 1025-1032 (2019).

93. Rissman, J. et al. Technologies and policies to decarbonize global industry: review and assessment of mitigation drivers through 2070. Appl. Energy 266, 114848 (2020).

94. Levesque, A., Pietzcker, R. C. \& Luderer, G. Halving energy demand from buildings: the impact of low consumption practices. Technol. Forecast. Soc. Change 146, 253-266 (2019).

95. Bodirsky, B. L. et al. The ongoing nutrition transition thwarts long-term targets for food security, public health and environmental protection. Sci. Rep. 10, 19778 (2020).

96. Valin, $H$. et al. The future of food demand: understanding differences in global economic models. Agric. Econ. 45, 51-67 (2014).

97. Banerjee, A., Niehaus, P. \& Suri, T. Universal basic income in the developing world. Annu. Rev. Econ. 11, 959-983 (2019).

98. Hubacek, K., Baiocchi, G., Feng, K. \& Patwardhan, A. Poverty eradication in a carbon constrained world. Nat. Commun. 8, 912 (2017).

99. Andrijevic, M., Crespo Cuaresma, J., Muttarak, R. \& Schleussner, C.-F. Governance in socioeconomic pathways and its role for future adaptive capacity. Nat. Sustain. 3, 35-41 (2020)

100. Hegre, H. et al. Forecasting civil conflict along the shared socioeconomic pathways. Environ. Res. Lett. 11, 054002 (2016).

101. Crespo Cuaresma, J. Income projections for climate change research: a framework based on human capital dynamics. Glob. Environ. Change 42, 226-236 (2017).

102. Andrijevic, M., Crespo Cuaresma, J., Muttarak, R. \& Schleussner, C.-F. Governance in socioeconomic pathways and its role for future adaptive capacity. Nat. Sustain. 3, 35-41 (2020).https://doi.org/10.1038/ s41893-019-0405-0

103. Rauner, S. et al. Coal-exit health and environmental damage reductions outweigh economic impacts. Nat. Clim. Change 10, 308-312 (2020).

104. Amann, M. The GAINS Integrated Assessment Model (European Consortium for Modelling of Air Pollution and Climate Strategies - EC4MACS, 2012); https://www.ec4macs.eu/content/report/EC4MACS_Publications/MR_ Final\%20in\%20pdf/GAINS_Methodologies_Final.pdf

105. Van Dingenen, R. et al. TM5-FASST: a global atmospheric source-receptor model for rapid impact analysis of emission changes on air quality and short-lived climate pollutants. Atmos. Chem. Phys. 18, 16173-16211 (2018),

106. Montoya, M. et al. The earth system model of intermediate complexity CLIMBER-3 $\alpha$. Part I: description and performance for present-day conditions. Clim. Dynam. 25, 237-263 (2005).

107. Fichefet, T. \& Maqueda, M. A. M. Sensitivity of a global sea ice model to the treatment of ice thermodynamics and dynamics. J. Geophys. Res. Oceans 102, 12609-12646 (1997).

108. Pacanowski, R. C. \& Griffies, S. M. The MOM-3 Manual (Geophysics Fluid Dynamics Laboratory/NOAA, 1999).

109. Hofmann, M. \& Maqueda, M. A. M. Performance of a second-order moments advection scheme in an Ocean General Circulation Model. J. Geophys. Res. Oceans 111, C05006 (2006).

110. Six, K. D. \& Maier-Reimer, E. Effects of plankton dynamics on seasonal carbon fluxes in an ocean general circulation model. Glob. Biogeochem. Cycles 10, 559-583 (1996).

111. Hofmann, M., Mathesius, S., Kriegler, E., van Vuuren, D. P. \& Schellnhuber, H. J. Strong time dependence of ocean acidification mitigation by atmospheric carbon dioxide removal. Nat. Commun. 10, 5592 (2019).

112. Soergel, B. et al. Data Repository - A Sustainable Development Pathway for Climate Action within the UN 2030 Agenda (Zenodo, 2021); https://doi. org/10.5281/zenodo.4787613

113. World Energy Outlook 2019 (IEA, 2019); https://www.iea.org/reports/ world-energy-outlook-2019

\section{Acknowledgements}

We thank D. Soergel for valuable comments on figure designs and proof-reading of the manuscript and F. Piontek, S. Madeddu and the other members of the REMIND and MAgPIE teams for helpful discussions. The SDG icons and circle used in the figures and tables were created by the United Nations: https://www.un.org/sustainabledevelopment/ sustainable-development-goals/. The content of this publication has not been approved by the United Nations and does not reflect the views of the United Nations or its officials or Member States. This work has been partially funded through the project SHAPE. SHAPE is part of AXIS, an ERA-NET initiated by JPI Climate and funded by FORMAS (SE), FFG/BMWFW (AT), DLR/BMBF (DE, grant no. 01LS1907A), NWO (NL) and 
RCN (NO) with cofunding by the European Union (grant no. 776608). This work was also supported by the European Union's Horizon 2020 research and innovation programme under grant nos. 821124 (NAVIGATE) and 821471 (ENGAGE). Further support is provided by the Global Commons Stewardship (GCS) project funded by the University of Tokyo/ Institute for Future Initiatives, and by the Food System Economics Commission (FSEC) funded by Rockefeller Foundation (no. 2020 FOD 008) and Wellcome Trust (no. 221362/Z/20/Z)

\section{Author contributions}

B.S. and E.K. designed the research with contributions from I.W., C.B., G.L. and the other authors. B.S., I.W., S.R. and A.D. performed the REMIND-MAgPIE modelling and the overall analysis, with contributions from the other authors. C.R., J.L. and C.W. performed the modelling for political institutions and conflict indicators. M.H. did the ocean modelling. B.S. and N.B. worked on the calculation of education and gender equality indicators. B.S. created all figures shown in the main paper; B.S., E.K., I.W., S.R., A.D. and C.R. created additional figures for the Extended Data and Supplementary
Information. B.S., E.K., I.W., S.R., A.D. and C.R. wrote the paper with contributions and feedback from all other authors.

\section{Competing interests}

The authors declare no competing interests.

\section{Additional information}

Extended data is available for this paper at https://doi.org/10.1038/s41558-021-01098-3. Supplementary information The online version contains supplementary material available at https://doi.org/10.1038/s41558-021-01098-3.

Correspondence and requests for materials should be addressed to B.S.

Peer review information Nature Climate Change thanks Alexandros Nikas, Toon Vandyck and the other, anonymous, reviewer(s) for their contribution to the peer review of this work.

Reprints and permissions information is available at www.nature.com/reprints. 


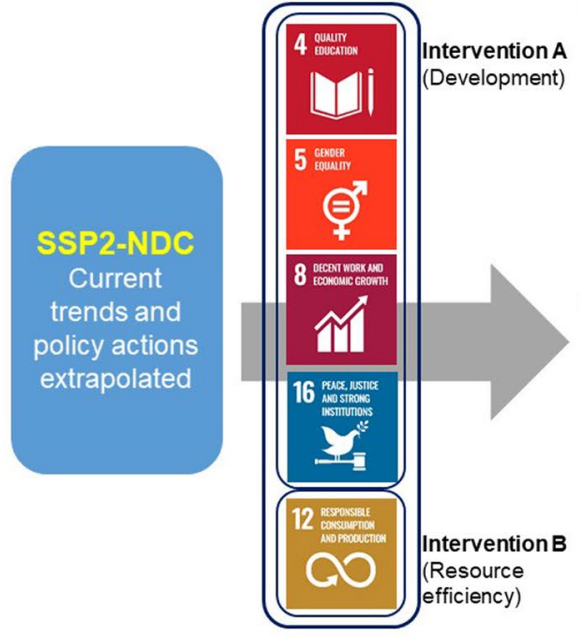

SSP1-1.5C

Policies enacted to

reach Paris climate goal

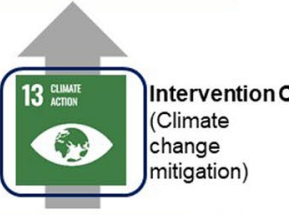

\section{SSP1-NDC}

New trends towards

sustainable develop-

ment enacted by

education initiatives,

resource efficiency,

environmentally

conscious lifestyles

and income conver-

gence. Climate action

continues to follow

current trends.

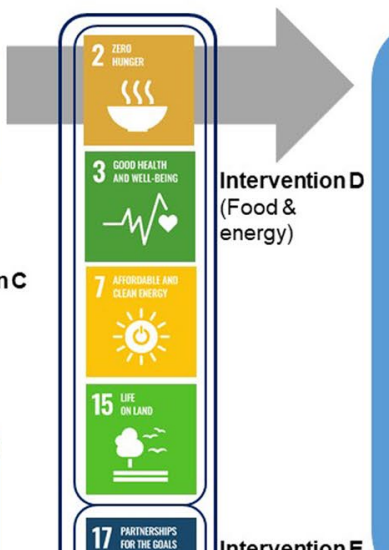
(Global equity)
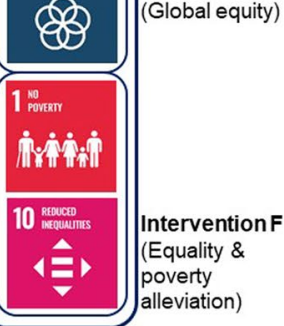

SDP-1.5C

Holistic SD policy

approach combining

Paris-consistent climate

policies with additional

action on healthy food

consumption (EAT-

Lancet), greater energy

access in least developed

regions, energy and land

system sustainability,

international transfers to

foster global cooperation,

and redistributive policies

to mitigate inequality and eliminate poverty.

Extended Data Fig. 1 | Illustration of the scenario setup for this study. The setup was designed to analyse the collective and individual impact of a range of sustainable development interventions: A - development, B - resource efficiency, C - climate change mitigation. D-food and energy: sufficient, healthy and sustainable nutrition; improved access to modern energy services in lower-income regions; ambitious shift to sustainable lifestyles in high-income regions; additional energy- and land-system sustainability policies. E - global equity: international burden sharing through climate and development finance. $\mathbf{F}$ - equality and poverty alleviation: progressive redistribution policies funded from the carbon pricing revenues. Note that the SDG icons attached to the interventions serve only as an illustration of the SDGs that are most strongly affected by the respective intervention, and are not intended to imply a specific grouping of SDGs. 


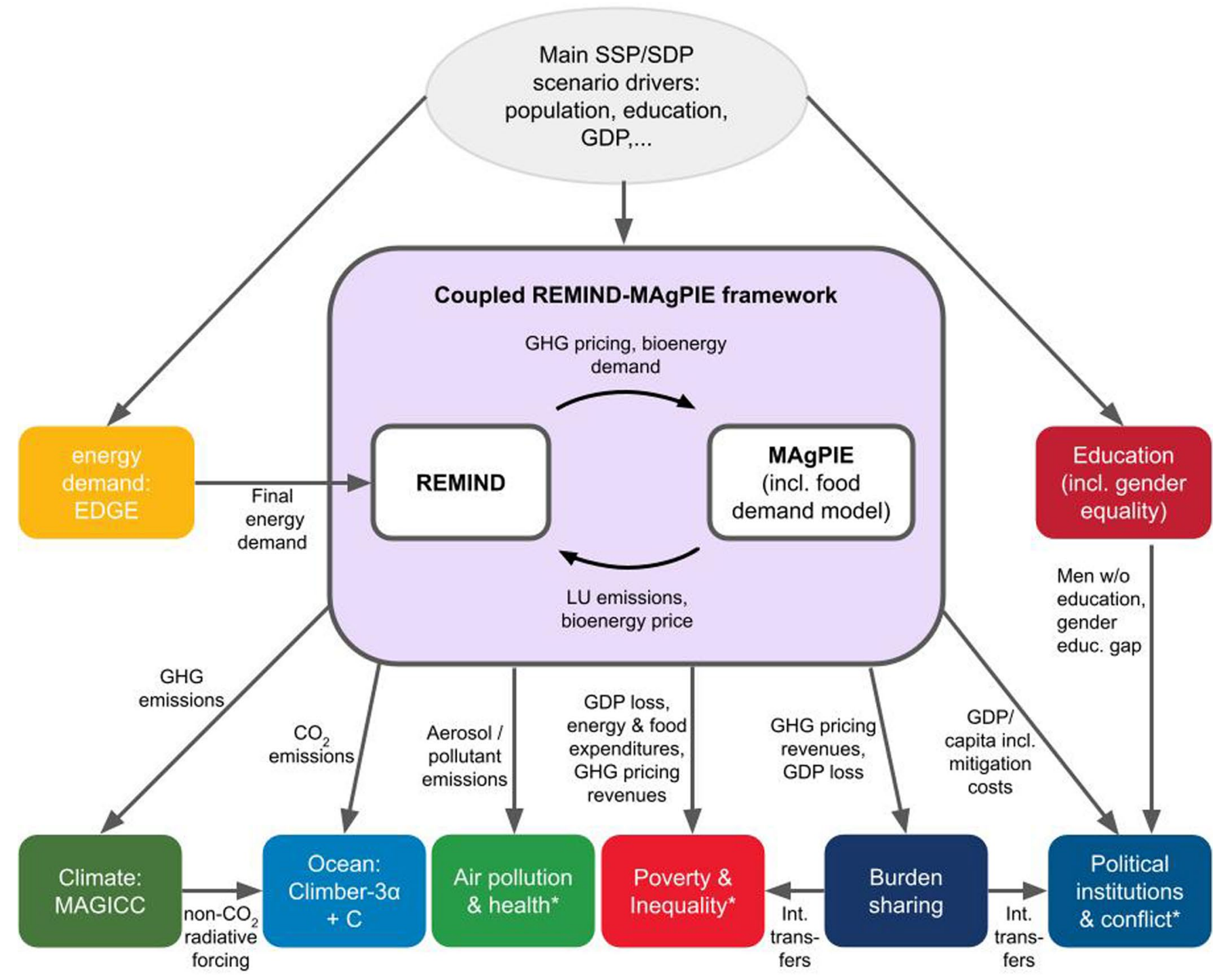

* post-processing models use additional SSP(-based) inputs, e.g. Gini coefficients, population downscaling, education projections

Extended Data Fig. 2 | Overview of the modelling framework. We show the linkages between the different models comprising our modelling framework built around REMIND-MAgPIE. The linkage between REMIND and MAgPIE is bi-directional (iterative soft coupling), the linkages to the downstream models for further SDG indicators are one-directional. The most relevant variables passed between models are specified next to the arrows. The colour-coding of the additional models broadly matches the SDGs they cover. 

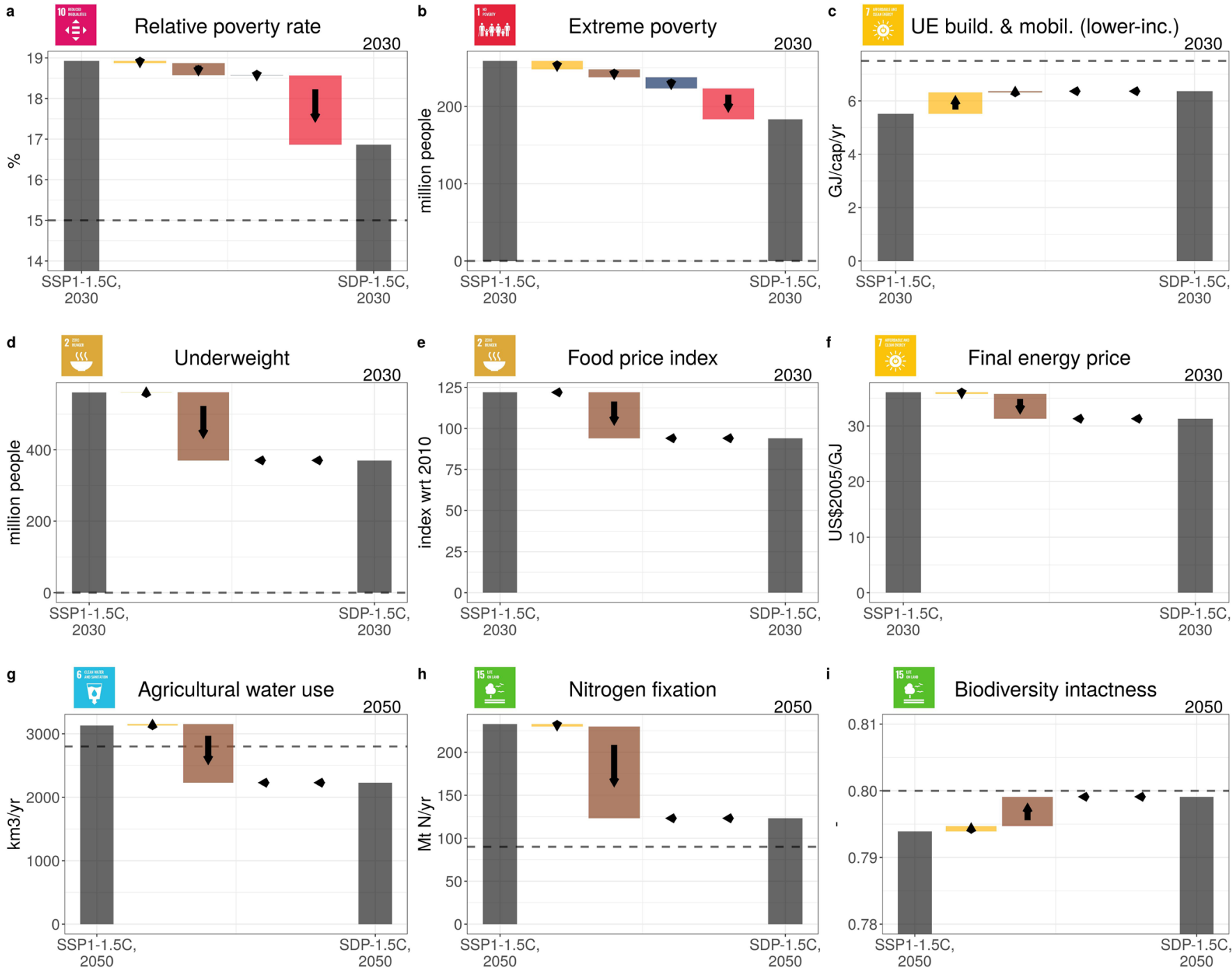

D-energy: demand \& supply

D-food: nutrition \& land use

E: global equity

F: national redistribution

Extended Data Fig. 3 | Decomposition of the SD interventions D-F. We unpack the additional SD interventions that are part of our SDP scenario (shown together in Fig. 2 in the main paper) into the steps D-energy (both demand \& supply), D-food (nutrition \& land use), E (global equity) and F (national redistribution). This decomposition highlights the effect of the individual interventions on the respective SDG indicator. Note that the interventions are 'applied' incrementally, that is we show the additional effect of an intervention starting from a scenario already including the previous interventions (same as in Fig. 2 in the main paper). Therefore the order of interventions matters in this decomposition. A more thorough discussion of this decomposition (including this figure) is given in SI Section 3. 
a

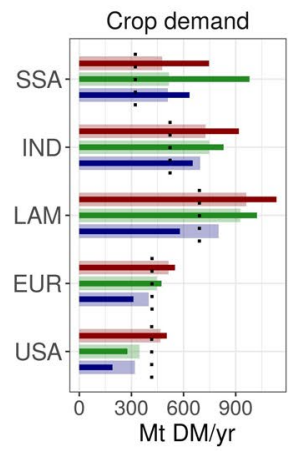

C

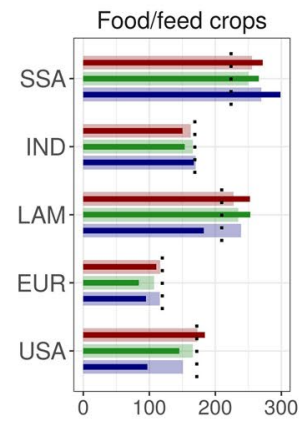

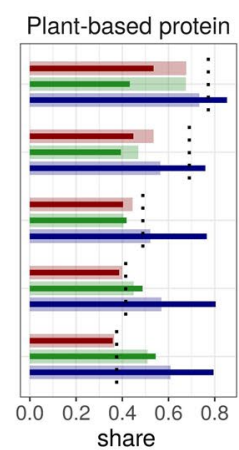

share

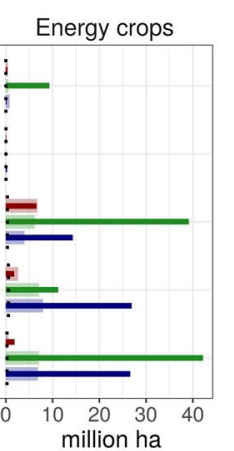

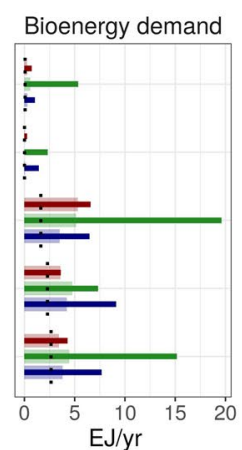

$\mathrm{EJ} / \mathrm{yr}$

b
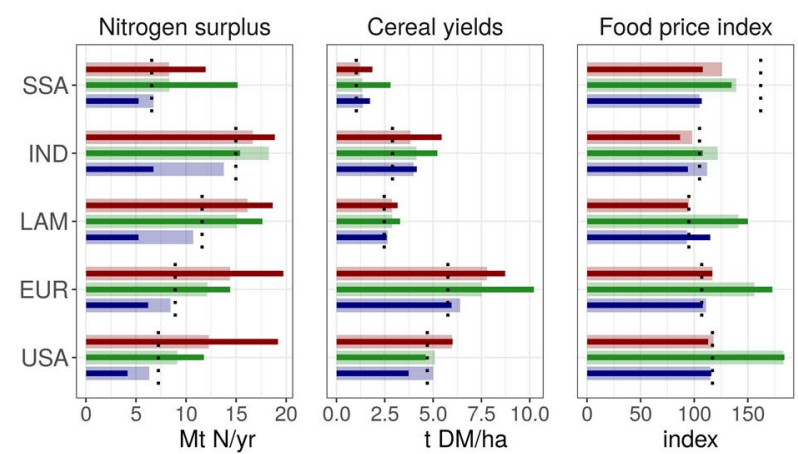

d

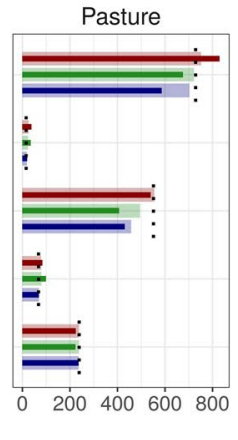

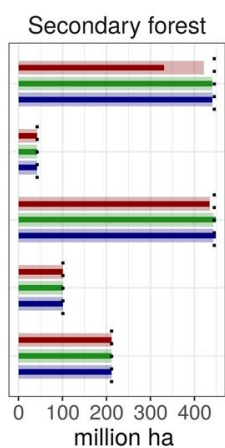

million ha

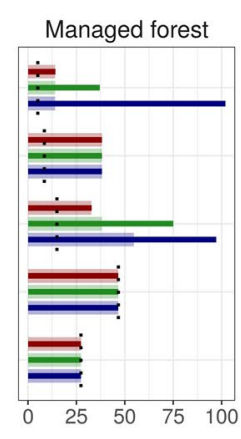

SDP-1.5C

SSP1-1.5C

SSP2-NDC

.. 2015

2030

2050

Extended Data Fig. 4 | Regional outcomes for selected indicators that describe key dynamics of the land and food system. Transparent wide bars represent 2030 values, solid thin bars are values for 2050 and the 2015 values are given by the dotted vertical lines. We show the SSP2-NDC (red, top), SSP1-1.5C (green, centre) and SDP-1.5C (blue, bottom) scenarios; the SSP1-NDC scenario is omitted for reasons of visual clarity. $\mathbf{a}$, Drivers of land use (crop demand, the share of plant-based protein in total dietary protein supply and bioenergy demand), $\mathbf{b}$, Production and food system characteristics ( $\mathrm{N}$ surplus on cropland, cereal yields and food price index w.r.t. 2010), c, Agricultural land (including cropland for food/feed crops and dedicated bioenergy crops as well as pasture) d, Forest cover differentiated between unmanaged (primary as well as secondary) forest and managed forest (including timber plantations and afforestation). Region abbreviations: Sub-Saharan Africa (SSA), India (IND), Latin America (LAM), European Union (EUR), United States of America (USA). A more detailed discussion on the land and food system (including this figure) is given in Section 4.1 of the SI. 
a Final energy demand

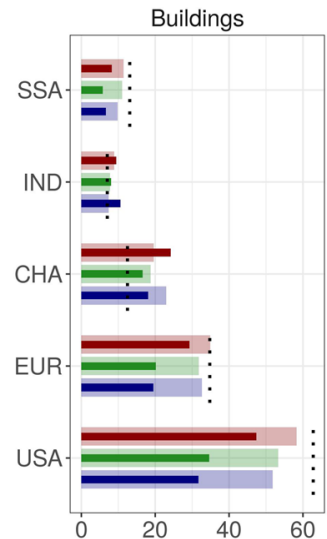

Industry

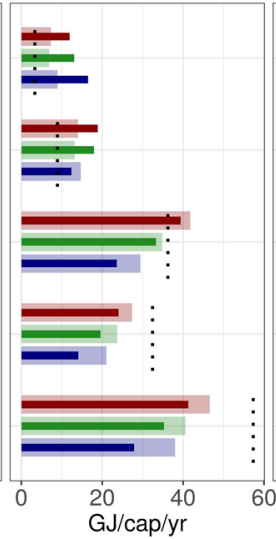

Transport

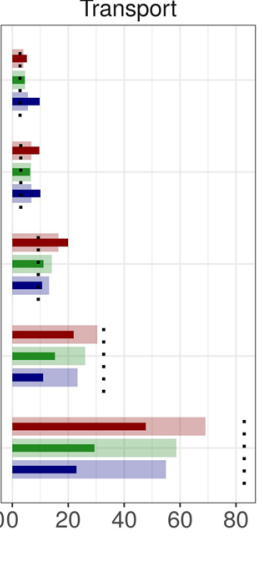

Share of clean final energy (electricity \& hydrogen)

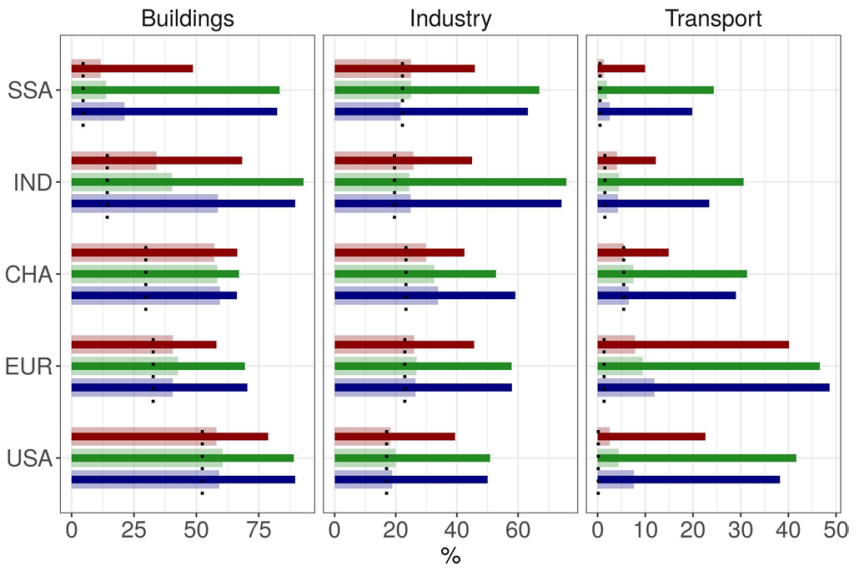

c Final energy demand

d

\section{CO2 emissions}

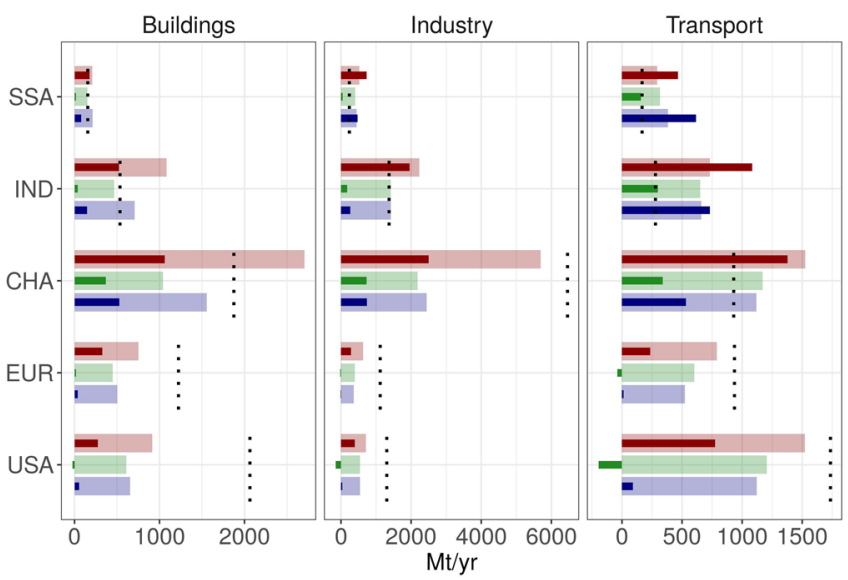

Extended Data Fig. 5 | Regional and sectoral outcomes for selected energy system dynamics indicators. Transparent wide bars represent 2030 values, solid thin bars are values for 2050, the 2015 values are given by the dotted vertical line. We show the SSP2-NDC (red, top), SSP1-1.5C (green, centre) and SDP-1.5C (blue, bottom) scenarios; the SSP1-NDC scenario is omitted for reasons of visual clarity. a, Sectoral final energy demand per capita, $\mathbf{b}$, Electricity and hydrogen share of final energy, by sector $\mathbf{c}$, Total final energy demand compared to the 2050 values of Grubler et al. ${ }^{34}$ and Millwards-Hopkins et al. ${ }^{43}$ and the 2030 values of the IEA 'Sustainable Development' scenario ${ }^{113}$. Note the imperfect mapping between the IEA 'Africa' region and our SSA region. The Grubler et al. model only distinguishes between two model regions (Global North and Global South). d, Sectoral CO2 emissions. Region abbreviations: Sub-Saharan Africa (SSA), India (IND), China (CHA), Europe (EUR), United States of America (USA). A more detailed discussion on the energy system (including this figure) is given in Section 4.2 of the $\mathrm{SI}$. 


\section{Reporting Summary}

Nature Research wishes to improve the reproducibility of the work that we publish. This form provides structure for consistency and transparency in reporting. For further information on Nature Research policies, see our Editorial Policies and the Editorial Policy Checklist.

\section{Statistics}

For all statistical analyses, confirm that the following items are present in the figure legend, table legend, main text, or Methods section.

n/a Confirmed

$\bigotimes$ The exact sample size $(n)$ for each experimental group/condition, given as a discrete number and unit of measurement

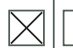

A statement on whether measurements were taken from distinct samples or whether the same sample was measured repeatedly

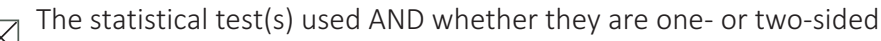

Only common tests should be described solely by name; describe more complex techniques in the Methods section.

$\bigotimes$ A description of all covariates tested

Х $\square$ A description of any assumptions or corrections, such as tests of normality and adjustment for multiple comparisons

$\checkmark$ A full description of the statistical parameters including central tendency (e.g. means) or other basic estimates (e.g. regression coefficient) AND variation (e.g. standard deviation) or associated estimates of uncertainty (e.g. confidence intervals)

For null hypothesis testing, the test statistic (e.g. $F, t, r$ ) with confidence intervals, effect sizes, degrees of freedom and $P$ value noted Give $P$ values as exact values whenever suitable.

Х $\square$ For Bayesian analysis, information on the choice of priors and Markov chain Monte Carlo settings

Х $\square$ For hierarchical and complex designs, identification of the appropriate level for tests and full reporting of outcomes

$\bigotimes \square$ Estimates of effect sizes (e.g. Cohen's d, Pearson's $r$ ), indicating how they were calculated

Our web collection on statistics for biologists contains articles on many of the points above.

\section{Software and code}

Policy information about availability of computer code

Data collection The IAM scenario data analysed in this paper are computed with the open-source IAM framework REMIND-MAgPIE (model versions: REMIND 2.1.3, MAgPIE 4.2.1); see also the code availability statement in the paper.

Data analysis Data analysis was performed using R-libraries that are specifically built for processing REMIND-MAgPIE outputs. These libraries are also available open source (https://github.com/pik-piam). Additional data analysis for the institutional quality-and conflict fatalities-model were performed in STATA (version 16.0.).

For manuscripts utilizing custom algorithms or software that are central to the research but not yet described in published literature, software must be made available to editors and

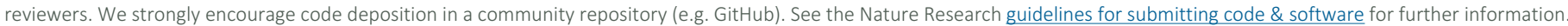

Data

Policy information about availability of data

All manuscripts must include a data availability statement. This statement should provide the following information, where applicable:

- Accession codes, unique identifiers, or web links for publicly available datasets

- A list of figures that have associated raw data

- A description of any restrictions on data availability

The data and analysis scripts supporting the findings of this study are available at https://doi.org/10.5281/zenodo.4787613. The following publicly accessible data sets were used for the the institutional quality and conflict fatalities models (see description in SI for references): Varieties of Democracy (V-Dem) [Country-Year/ Country-Data] Dataset Version 10, the Uppsala Conflict Data Program (UCDP) Georeferenced Event Dataset (GED) Global Version 20.1, and Population and Human Capital Stocks data by the Wittgenstein Centre. They can be accessed via the following links: https://www.v-dem.net/en/data/archive/previous-data/v-demdataset/; https://ucdp.uu.se/downloads/; http://dataexplorer.wittgensteincentre.org/wcde-v2/ 
Please select the one below that is the best fit for your research. If you are not sure, read the appropriate sections before making your selection.

Life sciences $\quad$ Behavioural \& social sciences $\square$ Ecological, evolutionary \& environmental sciences

For a reference copy of the document with all sections, see nature.com/documents/nr-reporting-summary-flat.pdf

\section{Behavioural \& social sciences study design}

All studies must disclose on these points even when the disclosure is negative.

Study description Model-based analysis of climate and sustainable development policies

Research sample $\quad$ For the model-based study, no research sample was selected. For the additional institutional quality- and conflict fatalities model country-year data for all countries with complete covariate information for the years 1995-2015 was obtained from the V-Dem [Country-Year/Country-Data] Dataset Version 10 (Coppedge et al. 2020; Pemstein et al. 2020), the Uppsala Conflict Data Program (UCDP) Georeferenced Event Dataset (GED) Global Version 20.1 (Sundberg and Melander 2013; Pettersson and Öberg 2020) and Population and Human Capital Stocks data by the Wittgenstein Centre (Lutz et al. 2018). The indicators used are described in the SI.

Sampling strategy

see above

Data collection

No additional data was collected during this study.

Timing

Does not apply since this study did not involve the collection of any additional data.

Data exclusions

see above

Non-participation

see above

Randomization

see above

\section{Reporting for specific materials, systems and methods}

We require information from authors about some types of materials, experimental systems and methods used in many studies. Here, indicate whether each material, system or method listed is relevant to your study. If you are not sure if a list item applies to your research, read the appropriate section before selecting a response.

\begin{tabular}{|c|c|c|c|}
\hline \multicolumn{2}{|r|}{ Materials \& experimental systems } & \multicolumn{2}{|c|}{ Methods } \\
\hline $\mathrm{n} / \mathrm{a}$ & Involved in the study & $\mathrm{n} / \mathrm{a}$ & Involved in the study \\
\hline$凶$ & $\square$ Antibodies & Х & ChIP-seq \\
\hline$\bigotimes$ & $\square$ Eukaryotic cell lines & Х & $\square$ Flow cytometry \\
\hline$\bigotimes$ & $\square$ Palaeontology and archaeology & Х & MRI-based neuroimaging \\
\hline 邓 & $\square$ Animals and other organisms & & \\
\hline 凶 & $\square$ Human research participants & & \\
\hline$凶$ & $\square$ Clinical data & & \\
\hline$\bigotimes$ & $\square$ Dual use research of concern & & \\
\hline
\end{tabular}

